\title{
Temporal and spatial variations and impact factors of nutrients in Bohai Bay, China
}

\author{
Xihan Liu ${ }^{\mathrm{a}, \mathrm{b}, \mathrm{c}, \mathrm{d}}$, Dongyan $\mathrm{Liu}^{\mathrm{a}, \mathrm{e}}$, Yujue Wang ${ }^{\mathrm{a}, *}$, Yajun Shi ${ }^{\mathrm{a}}$, Yanxia Wang ${ }^{\mathrm{c}, \mathrm{d}}$, Xiyan Sun ${ }^{\mathrm{f}}$ \\ ${ }^{a}$ CAS Key Laboratory of Coastal Environmental Processes and Ecological Remediation, Yantai Institute of Coastal Zone Research, Chinese Academy of Sciences, Yantai \\ 264003, PR China \\ ${ }^{\mathrm{b}}$ University of Chinese Academy of Sciences, Beijing 100049, PR China \\ ${ }^{\mathrm{c}}$ Hebei Joint Laboratory of Coastal Ecology and Environment, Institute of Geographical Sciences, Hebei Academy of Sciences, Shijiazhuang 050011, PR China \\ ${ }^{\mathrm{d}}$ Hebei Engineering Research Center for Geographic Information Application, Institute of Geographical Sciences, Hebei Academy of Sciences, Shijiazhuang 050011, PR \\ China \\ ${ }^{\mathrm{e}}$ State Key Laboratory of Estuarine and Coastal Research, East China Normal University, Shanghai 200062, PR China \\ ${ }^{\mathrm{f}}$ Muping Coastal Environment Research Station, Yantai Institute of Coastal Zone Research, Chinese Academy of Sciences, Yantai 264003, PR China
}

\section{A R T I C L E I N F O}

\section{Keywords:}

Nutrient

Distribution

Partition

Long-term variation

Bohai Bay

\begin{abstract}
A B S T R A C T
The temporal and spatial distributions of dissolved inorganic nitrogen (DIN), dissolved inorganic phosphorus (DIP), and dissolved silicate (DSi), and their long-term changes were investigated in Bohai Bay (BHB) in spring, summer, and autumn (2013-2014). The high DIN values were consistently distributed in the western inshore waters, mainly determined by terrestrial factors, e.g., riverine input, while DIP and DSi were mostly distributed in the southern coastal waters, the central BHB, or near the sea port Caofeidian in northern BHB, largely related to non-terrestrial factors, e.g., sediment release. Based on the nutrient distribution, BHB could be partitioned into western and eastern parts, with $-15 \mathrm{~m}$ depth as the separation. The long-term variations of nutrients since 2000 showed an increase in DIN and decreases in DIP and DSi. Relatively slow changes in DIN and DIP and a rapid decrease in DSi were exhibited in summer, which was associated with precipitation and sediment release.
\end{abstract}

\section{Introduction}

The explosive growth of the human population and the intensive impact of human activities, such as sewage disposal, fertilizer usage, water management, land reclamation, inshore fishing, and marine culture, have altered the global patterns of elemental cycling in recent decades (Carpenter and Bennett, 2011; De Vries et al., 2013). Nutrient over-enrichment that results from human activities is considered a major environmental problem, especially in coastal ecosystems around the world (Cloern et al., 2016; Glibert, 2017). For example, in Ariake Bay, Japan, a large reclamation project was conducted during $1986-1997$ to create nearly $35 \mathrm{~km}^{2}$ of land in tidal flats. Afterwards, the maximum velocity of the tidal current decreased by $10 \%-30 \%$, causing nutrients to accumulate in the surface seawater, which generated frequent harmful algal blooms (HABs) (Tsutsumi, 2006). A more daunting situation is that multiple anthropogenic pressures commonly coexist in the coastal seas, which simultaneously affect nutrient sources and sinks. Jiaozhou Bay, a eutrophic basin in northern China, has experienced an increase in nitrogen and a decrease in silicate during the most recent four decades, which was primarily associated with agricultural activities, precipitation, and wastewater input (Zhao et al., 2005). Reclamation, conducted in Jiaozhou Bay from 1966 to 2008, which decreased the water exchange speed by 7.5\% (Shi et al., 2011), was also a critical contributor to the increasing eutrophication in Jiaozhou Bay (Lin et al., 2016; Zhang et al., 2017). Therefore, which nutrient is changing and what are the related drivers are very ambiguous questions in coastal seas where multiple pressures coexist and interact (Cloern et al., 2016).

Bohai Bay (BHB) is a semi-enclosed bay in the western part of the Bohai Sea. The surrounding cities, such as Beijing, Tianjin, and Tangshan, have experienced rapid economic development in recent decades (Tong et al., 2014). Human activities related to rapid development are highly intensified and diversified, resulting in a significant impact on the nutrient regime. In previous studies, terrestrial factors, including sewage disposal, fertilizer usage, and water management were usually considered (Jiang et al., 2005; Ning et al., 2010). Nutrient concentrations in inshore waters, especially near the Hai River estuary, were ordinarily higher than in offshore waters (Zou et al., 1983; Lin et al., 1991; Shen, 1999). The impacts of atmospheric deposition and sediment release have been further emphasized in recent studies.

\footnotetext{
* Corresponding author.

E-mail address: yjwang@yic.ac.cn (Y. Wang).
} 


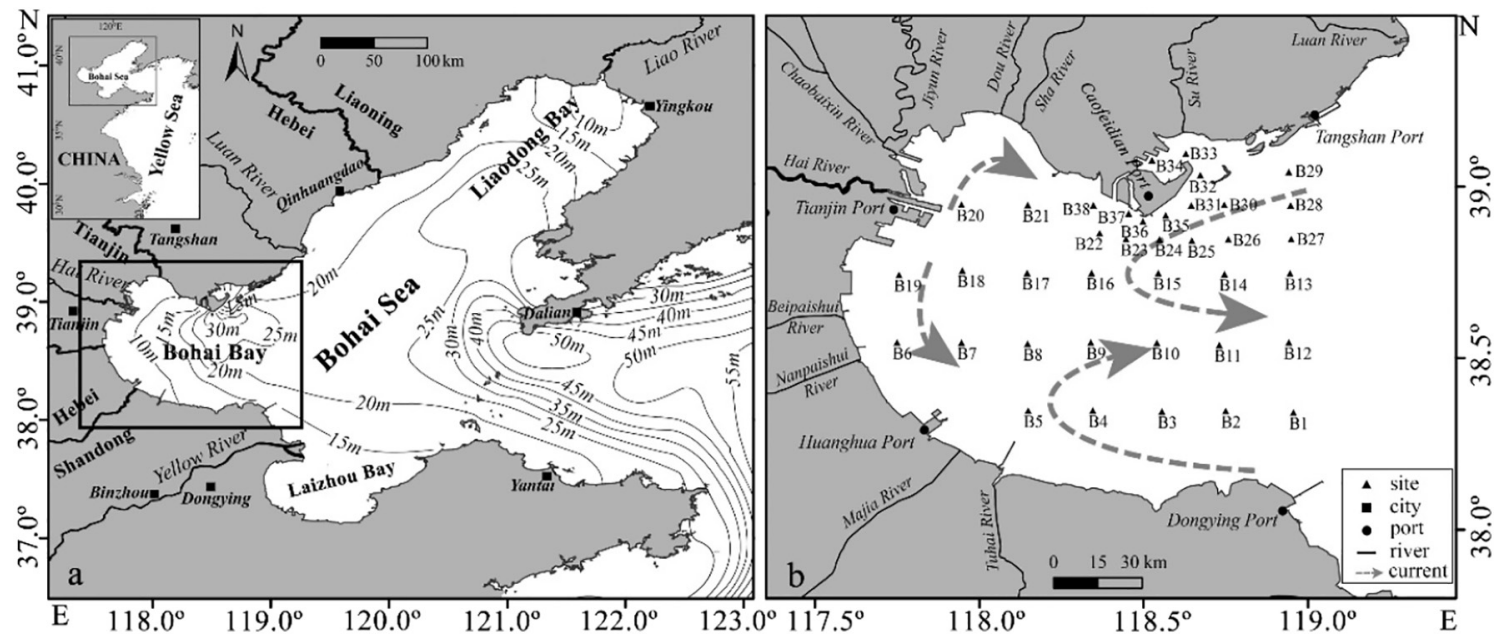

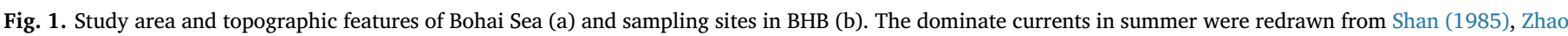
et al. (1995) and Wu et al. (2004). A same legend was shared by both figures.

Atmospheric nitrogen significantly exceeded that from riverine inputs, with a mean contribution of $84.79 \%$ to the total nitrogen concentration in the Bohai Sea (Shou et al., 2018). Zhang et al. (2016) reported that there was a hypoxia zone in the mouth of BHB, with dissolved oxygen (DO) content of $\sim 3 \mathrm{mg} \mathrm{L}^{-1}$. The anoxic condition would significantly increase the release of $\mathrm{P}$ and $\mathrm{Si}$ from the sediment to the overlying water (Belia et al., 2007; Song, 2010; Couceiro et al., 2013; Kang et al., 2018), which would influence the nutrient regime. Recent studies in BHB revealed that the high concentrations of DIP and DSi were more distributed in offshore waters than in inshore waters (Wang et al., 2009a; Li et al., 2012), suggesting that sediment release or exchange from other sea areas may result in a nonnegligible impact, which should be further investigated through additional field observations. Another important factor is coastal reclamation, which has been extensively conducted in BHB since 2000. In 1974-2004, reclamation was maintained at a low level of $30 \mathrm{~km}^{2} /$ a. However, it rapidly increased to $96.96 \mathrm{~km}^{2} / \mathrm{a}$ after 2004 (Zhu et al., 2016). During 2002-2012, the coastline increased by $311 \mathrm{~km}$, and the sea area decreased by $586.8 \mathrm{~km}^{2}$ (Zhu et al., 2014). An increase of $\sim 0.05 \mathrm{~m}$ in M2 tidal amplitude was obtained by both numerical models (Pelling et al., 2013) and the observation data of the Tianjin tidal gauge (Liu et al., 2017). Wang et al. (2015) indicated that water exchange and the average residence time changed remarkably, especially near coastal sea ports such as Tianjin, Caofeidian, and Huanghua, which were detrimental to the regional water quality. The combined influences from terrestrial inputs, atmospheric deposition, sediment release, and coastal reclamation not only control the nutrients sources and spatial distributions in BHB, but also resulted in long-term variations. During 1982-1998, DIN increased from $1.59 \mu \mathrm{ML}^{-1}$ to $7.25 \mu \mathrm{ML}^{-1}$, while DIP and DSi decreased from $1.18 \mu \mathrm{ML}^{-1}$ to $0.31 \mu \mathrm{ML}^{-1}$ and from $40.59 \mu \mathrm{ML}^{-1}$ to $17.43 \mu \mathrm{ML}^{-1}$, respectively (Jiang et al., 2005). Nevertheless, the characteristics of the nutrient regime, the dominant impact factors related to different regions of BHB, and the variations since 2000 have not been studied. Today, the "marine ecological civilization construction" policy in China emphasizes marine ecological and environmental protection, in which seawater pollution control and the regulations to clean up coastal waters (the "Blue Bay Regulations") of BHB are important tasks. Policymakers require references of the regional marine ecological environment state for the ecological remediation project. Therefore, understanding the temporal and spatial variations of nutrients and their impact factors are essential for sustainable development of BHB.

By monitoring nutrient concentrations together with other environmental factors during three cruises in spring, summer, and autumn in 2013-2014, and collecting and analyzing the historical data in the past 20 years in BHB, the specific objectives of this study could be met, including: 1) characterizing seasonal variations in the spatial distributions of nutrients and elucidating the impact factors of different nutrient species in different BHB regions, and 2) imaging the long-term seasonal and annual variation characteristics of different nutrient species in BHB and discussing their influence factors related to different human activities. We are hopeful that the results of this study will provide scientific support for seawater environmental management and Blue Bay Regulations in BHB.

\section{Material and methods}

\subsection{Study area}

BHB $\left(38^{\circ} 1^{\prime}-39^{\circ} 13^{\prime} \mathrm{N}, 117^{\circ} 36^{\prime}-119^{\circ} 8^{\prime} \mathrm{E}\right)$, located in the western Bohai Sea (Fig. 1a), is a shallow semi-enclosed basin with a mean depth of approximately $12.5 \mathrm{~m}$. The bay covers nearly $1.47 \times 10^{4} \mathrm{~km}^{2}$ and has vast mild-slope tidal flats in the intertidal zones (Nie and Tao, 2009). Since it is exposed to the eastern Asia monsoon, BHB is hot and rainy in summer, and cold and dry in winter. A southeast wind prevails in summer, while a northwest wind dominates in winter ( $\mathrm{Lv}$ et al., 2014). As much as $79.3 \%$ of the annual precipitation falls in the wet period from June to September (Wei et al., 2016). The prevailing wave directions are ENE and SSW, which account for $11.1 \%$ and $8.0 \%$ of the annual wave directions, respectively (Lv et al., 2014). The tidal current in BHB ranges from 20 to $80 \mathrm{~cm} / \mathrm{s}$, with the strongest tidal current occurring near Caofeidian (Bian et al., 2016). The circulation is ordinarily summarized as a two-loop structure in the mouth of BHB and two coastal currents in the western coastal waters (Fig. 1b). There are more than ten rivers flowing into BHB, e.g., Jiyun River, Chaobaixin River, Hai River, Beipaishui River and Nanpaishui River, in which Hai River, situated in Tianjin, is the largest river (Wei et al., 2016). Five large ports, including Tangshan Port, Caofeidian Port, Tianjin Port, Huanghua Port, and Dongying Port, are distributed surrounding BHB.

\subsection{Sampling and analysis}

In this study, three cruises took place in October 2013 (autumn), May 2014 (spring), and August 2014 (summer), respectively. The water samples in the surface and bottom layers were collected from $0.5 \mathrm{~m}$ below the surface and $1 \mathrm{~m}$ above the bottom, respectively, at 38 stations in BHB (Fig. 1b). A conductivity-temperature-depth profiler (RBR Concerto, Canada) was used to measure temperature (T), salinity (S), dissolved oxygen (DO), and turbidity in situ. The turbidity in autumn was not obtained because of instrument failure. Three replicate 1-L water samples were filtrated on board using GF/F filters (Whatman) 


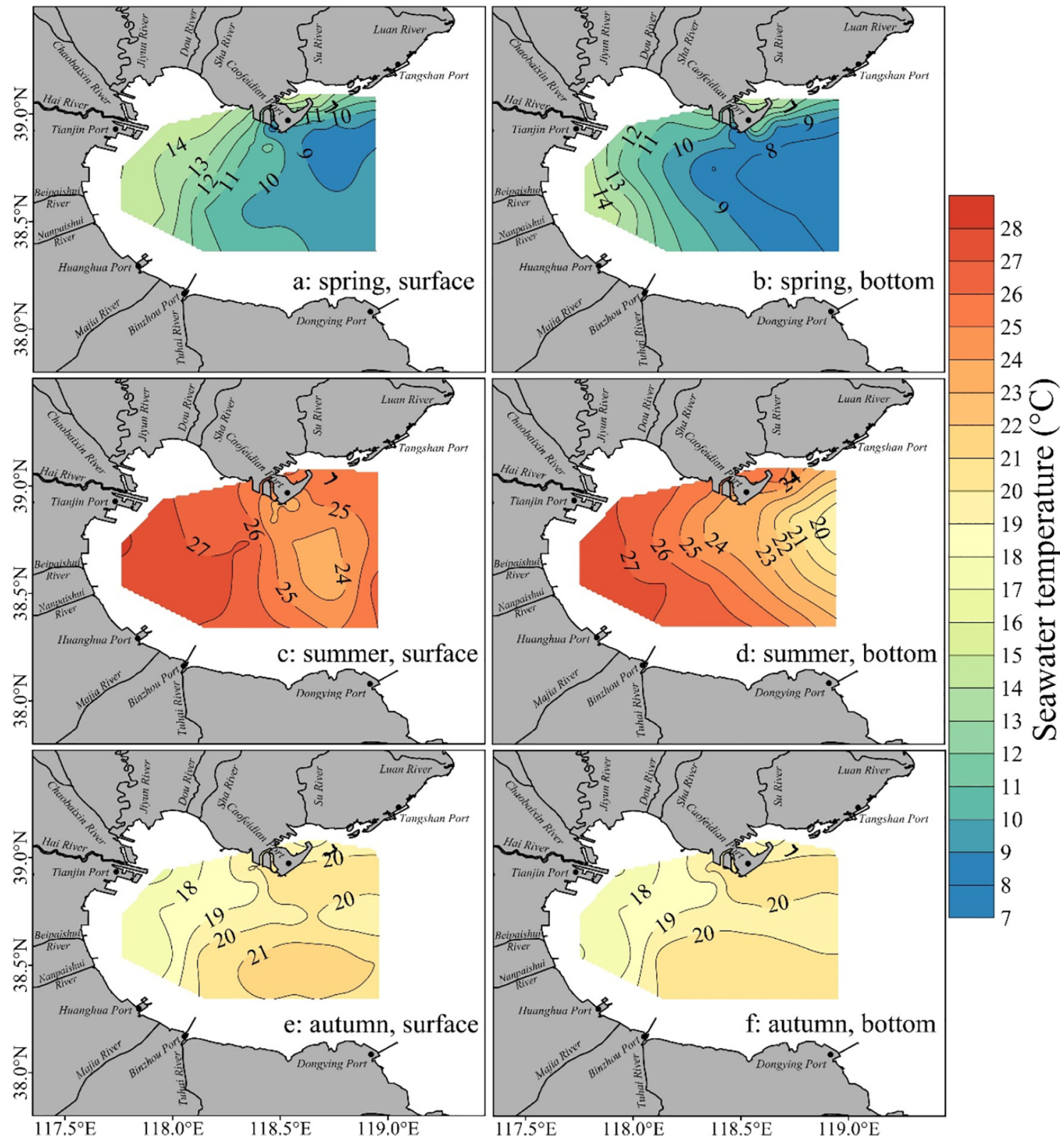

Fig. 2. The spatial distribution of temperature in BHB.

under low vacuum. Filters were then covered by foils and frozen at $-20^{\circ} \mathrm{C}$ for future chlorophyll- $a(\mathrm{Chl}-a)$ analysis, and the filtrate was frozen at $-20{ }^{\circ} \mathrm{C}$ for nutrient analysis. Chl- $a$ concentrations were detected following Lorenzen (1967): filters were extracted in $15 \mathrm{~mL}$ of $90 \%$ acetone, refrigerated in the dark for $24 \mathrm{~h}$, and then centrifuged at $4000 \mathrm{rpm}$ for $10 \mathrm{~min}$ to obtain clear extracts. The extracts were then detected at $750 \mathrm{~nm}, 664 \mathrm{~nm}, 647 \mathrm{~nm}$, and $630 \mathrm{~nm}$, using a spectrophotometer (TU-1800, Persee, China). Nutrients including DIN $\left(\mathrm{NO}_{3}{ }^{-}+\mathrm{NO}_{2}{ }^{-}+\mathrm{NH}_{4}{ }^{+}\right)$, DIP, and DSi were quantified using flow injection analysis (AA3, Bran + Luebbe, Germany) after thawing the samples at $4^{\circ} \mathrm{C}$ (Bran + Luebbe, 2008a, 2008b, 2008c, 2008d, 2008e).

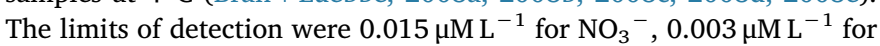
$\mathrm{NO}_{2}{ }^{-}, 0.04 \mu \mathrm{ML}^{-1}$ for $\mathrm{NH}_{4}{ }^{+}, 0.02 \mu \mathrm{ML}^{-1}$ for DIP, and $0.03 \mu \mathrm{ML}^{-1}$ for DSi.

\subsection{Data analysis}

The graphs of the isoline distribution of seawater temperature, salinity, DO, turbidity, nutrients, and Chl- $a$ were plotted using Surfer
12.0. Cluster analysis and regression analysis were completed using the R package 3.3.2 (R Core Team, 2017). The cluster analysis used the partitioning around medoids (PAM) scheme to partition sampling stations by nutrients with Vegan 2.4.3 (Oksanen et al., 2016). The regression analyses were performed using the generalized linear model (GLM) in ggplot2 (Wickham, 2016). The paired and independent $t$-test was conducted with SPSS 20.0 (SPSS Inc., USA).

\section{Results}

\subsection{Seawater temperature and salinity}

The sea surface temperature of BHB was $11.10 \pm 2.24^{\circ} \mathrm{C}$ in spring, $25.68 \pm 1.32{ }^{\circ} \mathrm{C}$ in summer, and $19.71 \pm 1.32{ }^{\circ} \mathrm{C}$ in autumn, while the sea bottom temperature was $10.04 \pm 2.41{ }^{\circ} \mathrm{C}$ in spring, $24.15 \pm 2.36{ }^{\circ} \mathrm{C}$ in summer, and $19.59 \pm 1.20^{\circ} \mathrm{C}$ in autumn (Fig. 2). The seasonal variation in seawater temperature corresponded to the meteorological characteristics in BHB, with warm seawater in summer and relatively cool seawater in spring. The inshore shallow waters in 


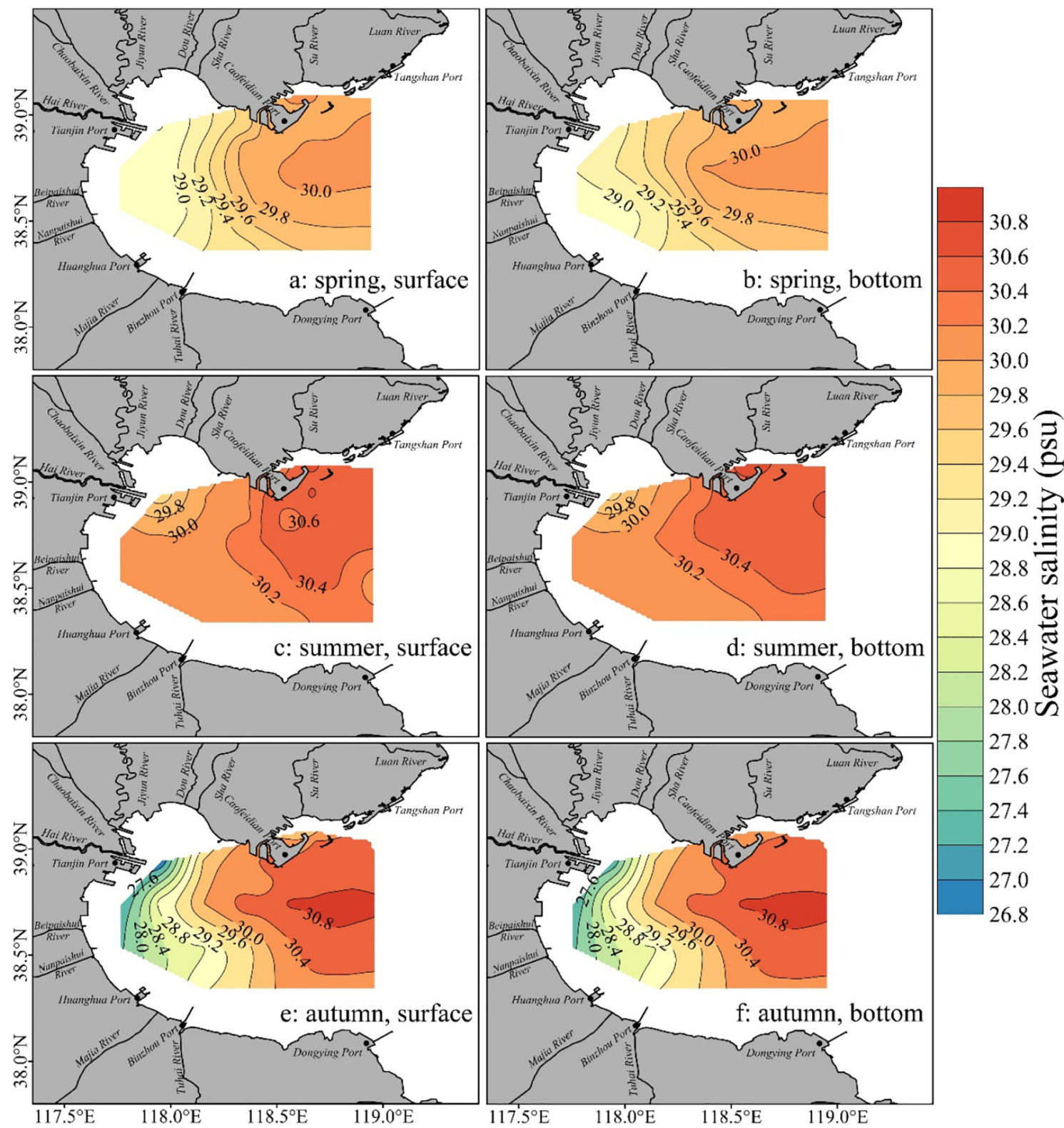

Fig. 3. The spatial distribution of salinity in BHB.

the western BHB were more susceptible to the terrestrial climate than the offshore waters. The land temperature surrounding BHB was higher in spring and summer and lower in autumn and winter compared to the sea temperature. As a result, the sea temperature in both the surface and bottom layers in BHB basically presented a declining gradient, from inshore shallow water to offshore deep water in spring and summer, and the opposite gradient distribution in autumn. A surface cold center (approximately $24^{\circ} \mathrm{C}$ ) was found near the mouth of BHB in summer, while two warm centers (approximately $21^{\circ} \mathrm{C}$ ) were found in autumn near the southern and northern coasts.

The sea surface salinity was $29.67 \pm 0.42$ in spring, $30.30 \pm 0.25$ in summer, and $29.96 \pm 1.06$ in autumn, while the sea bottom salinity was $29.73 \pm 0.38$ in spring, $30.34 \pm 0.25$ in summer, and $29.99 \pm 1.02$ in autumn (Fig. 3). Seasonal variations in salinity were mainly related to freshwater loading. The runoff from the major rivers in BHB was $66.14 \times 10^{8} \mathrm{~m}^{3}$ in autumn $2013,49.37 \times 10^{8} \mathrm{~m}^{3}$ in spring 2014 , and $35.20 \times 10^{8} \mathrm{~m}^{3}$ in summer 2014 (Department of Water Resources of Hebei Province, 2013-2014). The runoff led to the relatively low salinity in autumn and high salinity in summer. The spatial distribution in the three seasons exhibited low salinity in the western inshore waters and high values in the eastern offshore waters, which suggests that the western inshore waters were more affected by freshwater inputs from the surrounding rivers.

\subsection{Seasonal and spatial variations of $D O$}

Significant seasonal variations of DO were found in this study, with the highest concentrations in autumn (surface water: $8.71 \pm 0.53 \mathrm{mg} \mathrm{L}^{-1}$; bottom water: $8.41 \pm 0.53 \mathrm{mg} \mathrm{L}^{-1}$ ) and the lowest concentrations in summer (surface water: $4.62 \pm 0.67 \mathrm{mg} \mathrm{L}^{-1}$; bottom water: $3.76 \pm 0.75 \mathrm{mg} \mathrm{L}^{-1}$ ). DO concentrations in spring were $6.91 \pm 0.42 \mathrm{mg} \mathrm{L}^{-1}$ in the surface water and $6.91 \pm 0.41 \mathrm{mg} \mathrm{L}^{-1}$ in the bottom water (Fig. 4). The spatial distribution of DO showed significant seasonal variations. In spring, it generally followed a gradient distribution from inshore to offshore waters. In summer, DO in the surface was patchily distributed, with a high DO zone $\left(>5 \mathrm{mg} \mathrm{L}^{-1}\right)$ that was observed between Tianjin and Caofeidian, while DO at the bottom showed a similar gradient distribution with spring. However, DO was rather low $\left(<3 \mathrm{mg} \mathrm{L}^{-1}\right)$ near the mouth of $\mathrm{BHB}$, corresponding with recent observations in the Bohai Sea (Zhai et al., 2012; Zhang 


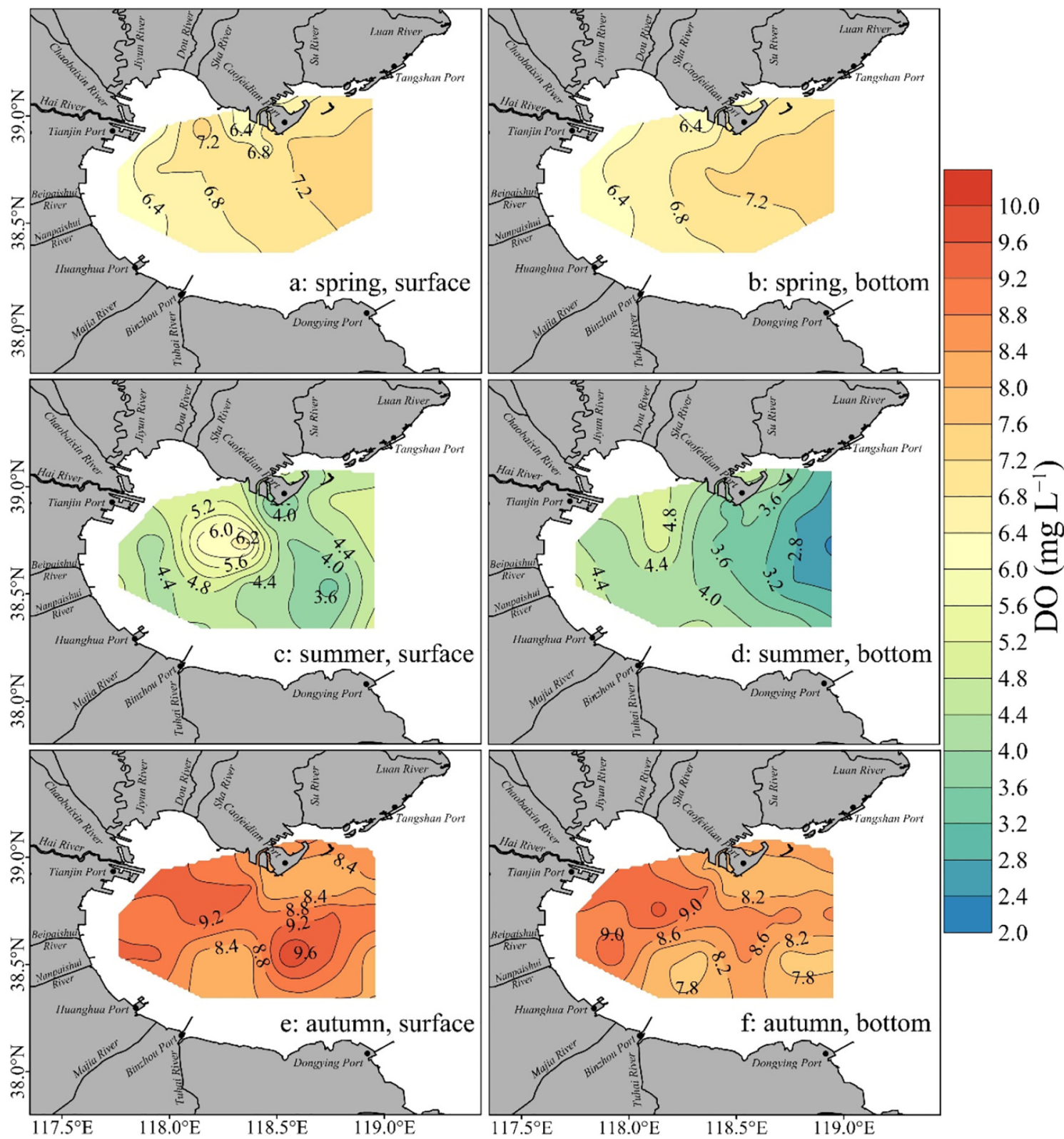

Fig. 4. The spatial distribution of DO in BHB.

et al., 2016; Zhao et al., 2017), while DO was relatively high in the western coastal waters. In autumn, a strip of high DO concentrations (approximately $9 \mathrm{mg} \mathrm{L}^{-1}$ ) was distributed from Tianjin to the central sea area of BHB, while the DO of the other sea area was relatively low $\left(7.8-8.4 \mathrm{mg} \mathrm{L}^{-1}\right)$.

\subsection{Seasonal and spatial variations of turbidity}

The turbidity was higher in spring (surface seawater: $11.70 \pm 9.60$ NTU; bottom seawater: $60.34 \pm 60.50 \mathrm{NTU}$ ) and lower in summer (surface seawater: $5.88 \pm 4.54 \mathrm{NTU}$; bottom seawater: $37.23 \pm 34.47$ NTU) (Fig. 5). Generally, the wind in spring was relatively strong, which resulted in a greater disturbance to the bottom of the sea and generated more sediment resuspension (Lv et al., 2014; Wang et al., 2014). As a result, turbidity in spring was ordinarily higher than that in summer, especially for bottom waters, which were more affected by sediment resuspension. In spring, high values of turbidity were distributed in the southern coastal waters in BHB, where turbidity at the bottom reached 260 NTU. In summer, high concentrations were observed near Huanghua, which was extended along the shore at the surface and to the central area of BHB at the bottom. Sea areas near Caofeidian consistently exhibited relatively high turbidity in both spring and summer, which corresponded to their strong tidal currents, suggesting significant sediment resuspension.

\subsection{Seasonal and spatial variations of nutrients}

\subsubsection{DIN}

Seasonal variations showed that DIN accumulated in spring, with concentrations reaching $15.32 \pm 7.63 \mu \mathrm{M} \mathrm{L}^{-1}$ in the surface water and $14.78 \pm 10.56 \mu \mathrm{M} \mathrm{L}^{-1}$ in the bottom water (Fig. 6). In summer, DIN declined to $7.37 \pm 5.51 \mu \mathrm{ML}^{-1}$ (surface water) and $8.20 \pm 4.65 \mu \mathrm{ML}^{-1}$ (bottom water), and in autumn, DIN re-accumulated and increased to $10.42 \pm 4.29 \mu \mathrm{ML}^{-1}$ (surface water) and $10.04 \pm 4.87 \mu \mathrm{ML}^{-1}$ (bottom water). Spatially, the DIN distribution across the three seasons were rather similar, with high values observed in inshore waters near Tianjin and Huanghua, which suggested that terrestrial input was an important source of DIN. 


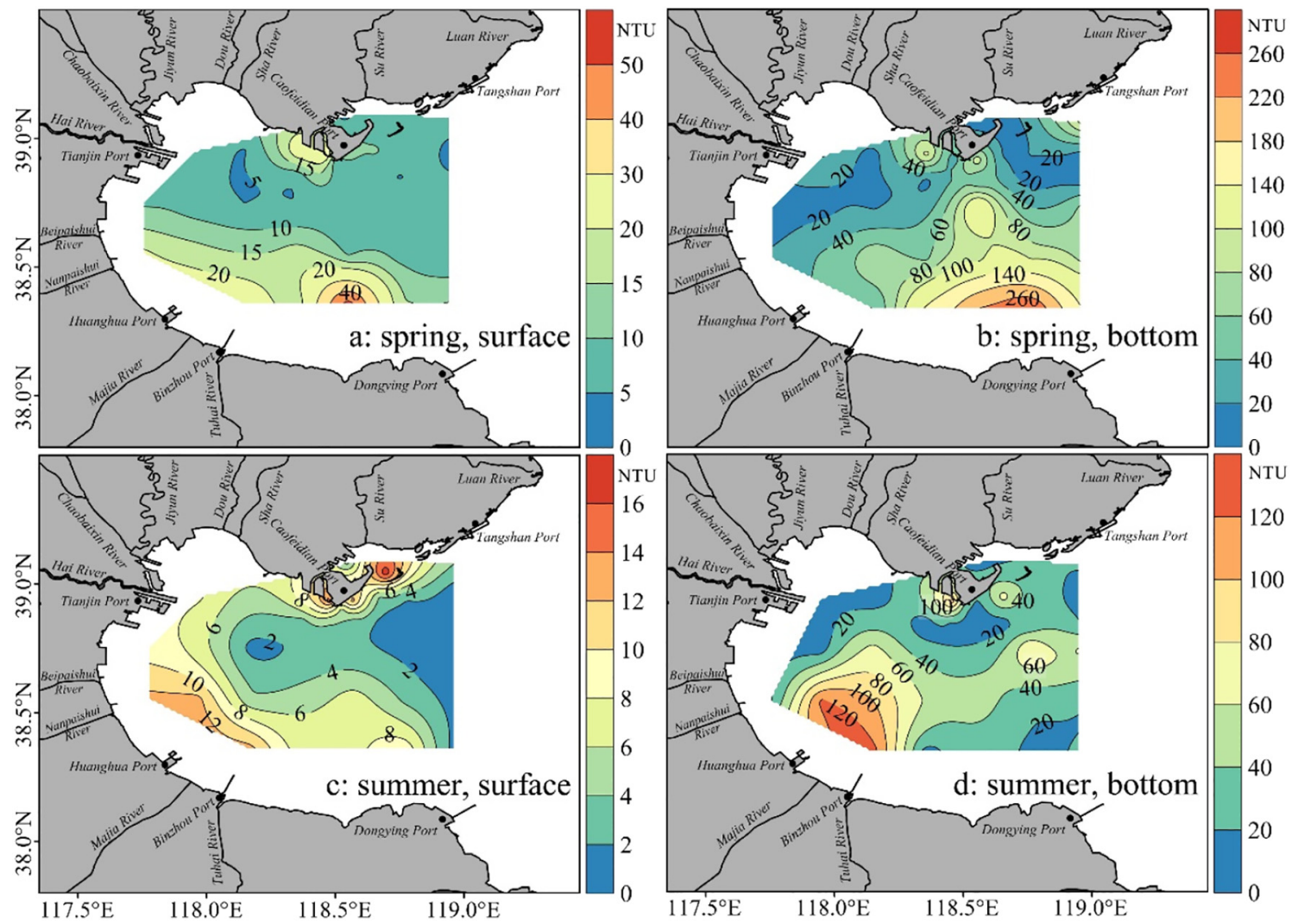

Fig. 5. The spatial distribution of turbidity in BHB.

\subsubsection{DIP}

Unlike the seasonal variations of DIN, high DIP concentrations were found in summer, with values of $0.19 \pm 0.06 \mu \mathrm{M} \mathrm{L}^{-1}$ in the surface and bottom water, while low concentrations $\left(0.13 \pm 0.01 \mu \mathrm{ML}^{-1}\right.$ in the surface water and $0.14 \pm 0.03 \mu \mathrm{ML}^{-1}$ in the bottom water) occurred in autumn. In spring, the mean DIP concentration in the surface water was $0.16 \pm 0.01 \mu \mathrm{ML}^{-1}$ and $0.16 \pm 0.02 \mu \mathrm{ML}^{-1}$ in the bottom water (Fig. 7). In spring, the western, northern, and southern coastal waters all had relatively high DIP concentrations, while the central sea area of BHB had low DIP values. In summer, the high DIP zone extended from Caofeidian to the mouth of BHB, and the coastal water near Tianjin was also a small sea area with high DIP concentrations. The DIP distribution in autumn was similar to that in summer, with a high DIP zone distributed near Caofeidian. However, it was smaller in coverage and lower in concentration.

\subsection{3. $D S i$}

DSi concentrations of BHB were $3.06 \pm 1.98 \mu \mathrm{ML}^{-1}$ (surface water) and $3.62 \pm 3.04 \mu \mathrm{M} \mathrm{L}^{-1}$ (bottom water) in spring, $3.34 \pm 1.26 \mu \mathrm{ML}^{-1}$ (surface water) and $3.55 \pm 1.65 \mu \mathrm{M} \mathrm{L}^{-1}$ (bottom water) in summer, and $4.69 \pm 2.60 \mu \mathrm{ML}^{-1}$ (surface water) and $4.47 \pm 2.59 \mu \mathrm{M} \mathrm{L}^{-1}$ (bottom water) in autumn (Fig. 8). In spring, high concentrations of DSi were distributed in the southern coastal waters, where DSi at the bottom was higher than that at the surface. Inshore waters near Tianjin also had relatively high DSi concentrations. In summer, the high DSi zone at the surface was distributed in the central area and the mouth of BHB, and that at the bottom extended from the northern BHB to the central area of BHB. In autumn, both the surface and bottom waters exhibited a high DSi zone west of Caofeidian and diffused in the southeast direction.

\subsection{Seasonal and spatial variations of Chl-a}

The seasonal variations in Chl- $a$ showed low concentrations in spring $\quad\left(2.16 \pm 1.69 \mu \mathrm{gL}^{-1} \quad\right.$ in the surface water and $2.22 \pm 1.25 \mu \mathrm{g} \mathrm{L}^{-1}$ in the bottom water), high concentrations of $6.46 \pm 3.92 \mu \mathrm{g} \mathrm{L}^{-1}$ (surface water) and $5.32 \pm 2.77 \mu \mathrm{g} \mathrm{L}^{-1}$ (bottom water) in summer, and concentrations of $2.26 \pm 1.85 \mu \mathrm{g} \mathrm{L}^{-1}$ (surface water) and $2.23 \pm 1.59 \mu \mathrm{L}^{-1}$ (bottom water) in autumn (Fig. 9). Spatially, in spring, the higher Chl- $a$ values were mostly distributed in the western and northern coastal waters. The Chl- $a$ in the central sea area in BHB was as low as approximately $1 \mu \mathrm{g} \mathrm{L}^{-1}$. In summer and autumn, high Chl- $a$ concentrations were always evident east of Tianjin Port, spread to the southeast. Some stations near the mouth of BHB in summer also had relatively high Chl- $a$ values of approximately $7 \mu \mathrm{g} \mathrm{L}{ }^{-1}$. An extremely high Chl- $a$ of $8 \mu g \mathrm{~L}^{-1}$ was recorded at the surface water at Station 11 in autumn, which far exceeded that in the bottom water and that at neighboring sites. According to in situ observations, there were brown stripes on the surface of the seawater, which suggested that a small algae bloom was possibly developing in that sea area.

\section{Discussion}

\subsection{Sources and impact factors related to the spatial distributions of} nutrients

The spatial distributions of nutrients in the three seasons indicated different sources and impact factors for DIN, DIP, and DSi. Terrestrial input, atmospheric deposition, and sediment release have usually been considered as the three main sources of nutrients in Bohai Sea, while the fluxes via these sources vary with nutrient species and physicochemical conditions (Liu et al., 2003; Song, 2010). Additionally, hydrodynamic conditions play an important role in the process of nutrient transportation (Millero, 2013).

For DIN, terrestrial input, atmospheric deposition, and sediment release are important sources (Liu et al., 2003). Terrestrial nutrients are mostly transported into the sea by rivers surrounding BHB, and these 


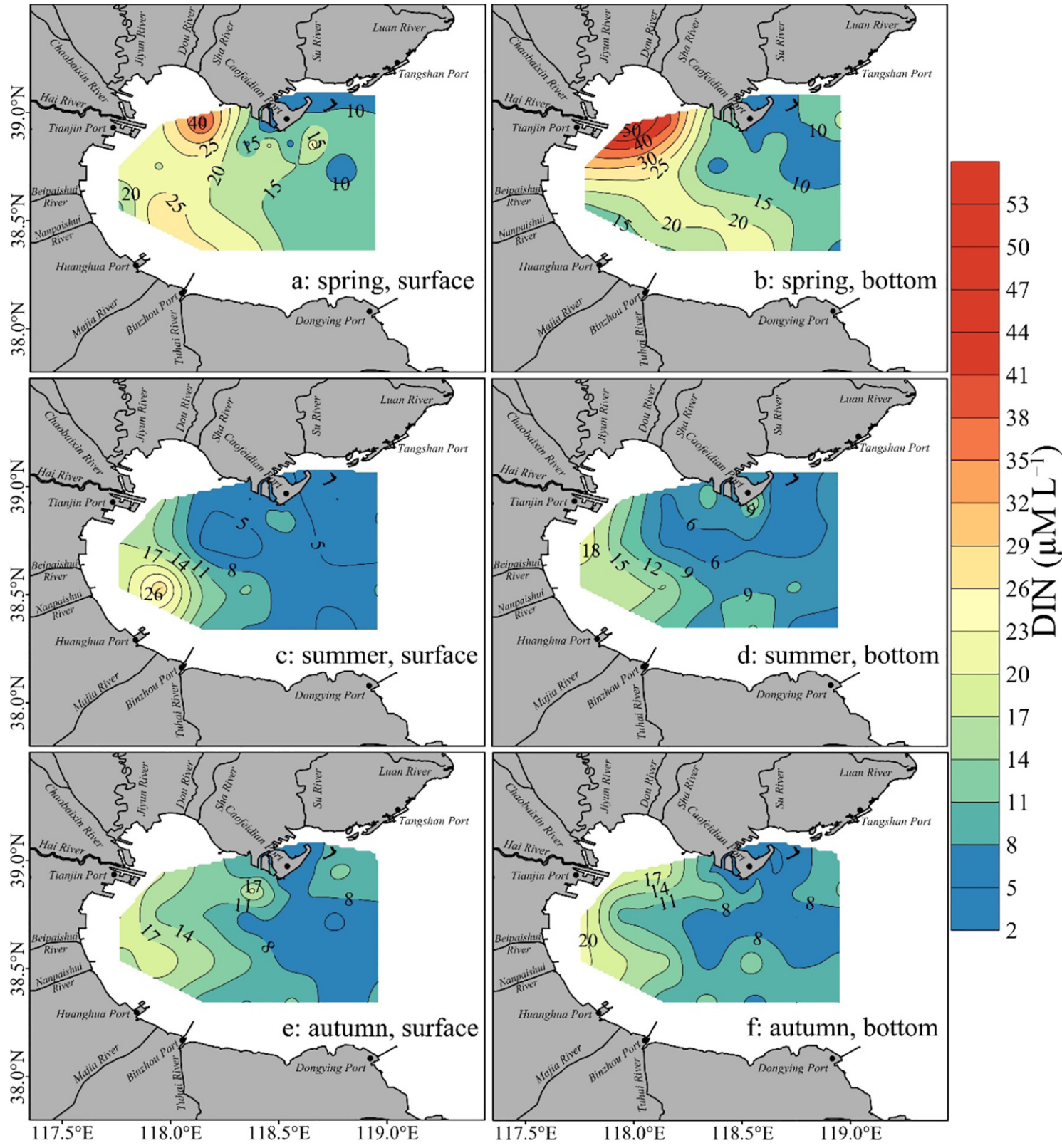

Fig. 6. The spatial distribution of DIN in BHB.

rivers all belong to the Hai River Basin. The land covered by the Hai River Basin is one of the most populated and industrialized regions in China, e.g., Beijing, Tianjin, Hebei, and Shandong, as well as nearly half of the North China Plain, an important farming region (Chu et al., 2010a). Therefore, a large amount of $\mathrm{N}$ entered the rivers due to wastewater direct discharge, fertilizer usage, and soil loss. It was estimated that riverine total nitrogen $(\mathrm{TN})$ reached $88.39 \times 10^{4}$ t/a (Huang et al., 2013), and as much as $44 \%$ of these rivers experienced severe eutrophication (Zhang et al., 2015). Moreover, the estuaries of these rivers are concentrated along the western coasts, e.g., Hai River, Chaobaixin River, and Majia River, which cause the western inshore waters to be significantly affected by riverine inputs, as reflected in our study, showing that high values of DIN always occurred in the western coastal waters (Fig. 6). Atmospheric nitrogen deposition affected the spatial and temporal distributions of DIN in the Bohai Sea, with BHB as the most polluted area, especially in the western inshore waters, such as Tianjin and Huanghua (Shou et al., 2018). The sediment is ordinarily a source for ammonium and a sink for nitrate and nitrite in Bohai Sea, in which the ammonium represents $88 \%$ of the benthic fluxes of DIN and is mainly migrated from sediment to seawater (Liu et al., 2011). According to the paired $t$-test of the percentage of ammonium in DIN, there was no significant difference between surface and bottom $(p>0.05)$ in all three seasons. In addition, DIP and DSi, for which sediment is an important source, mostly showed no significant differences between surface and bottom $(p>0.05)$. In BHB, a shallow basin with an average depth of $12.5 \mathrm{~m}$, strong vertical water mixing exists (Huang et al., 1999) and transports nutrients released from sediment upwards, causing little difference between surface and bottom. Therefore, the release of ammonium from sediment could not be ruled out without further evidence, despite no significant difference observed.

The spatial distribution of DIP varied over the three seasons, suggesting its determining factor may have varied with seasons. In previous studies, high values of DIP were ordinarily distributed near the Hai River estuary (Peng, 2015), which is similar to the situation in spring and summer in this study (Fig. 7), suggesting impacts from riverine inputs. However, due to the seasonal variations of total runoff surrounding BHB, the freshwater input in autumn was more significant during this investigation (Fig. 3) although this did not lead to the 


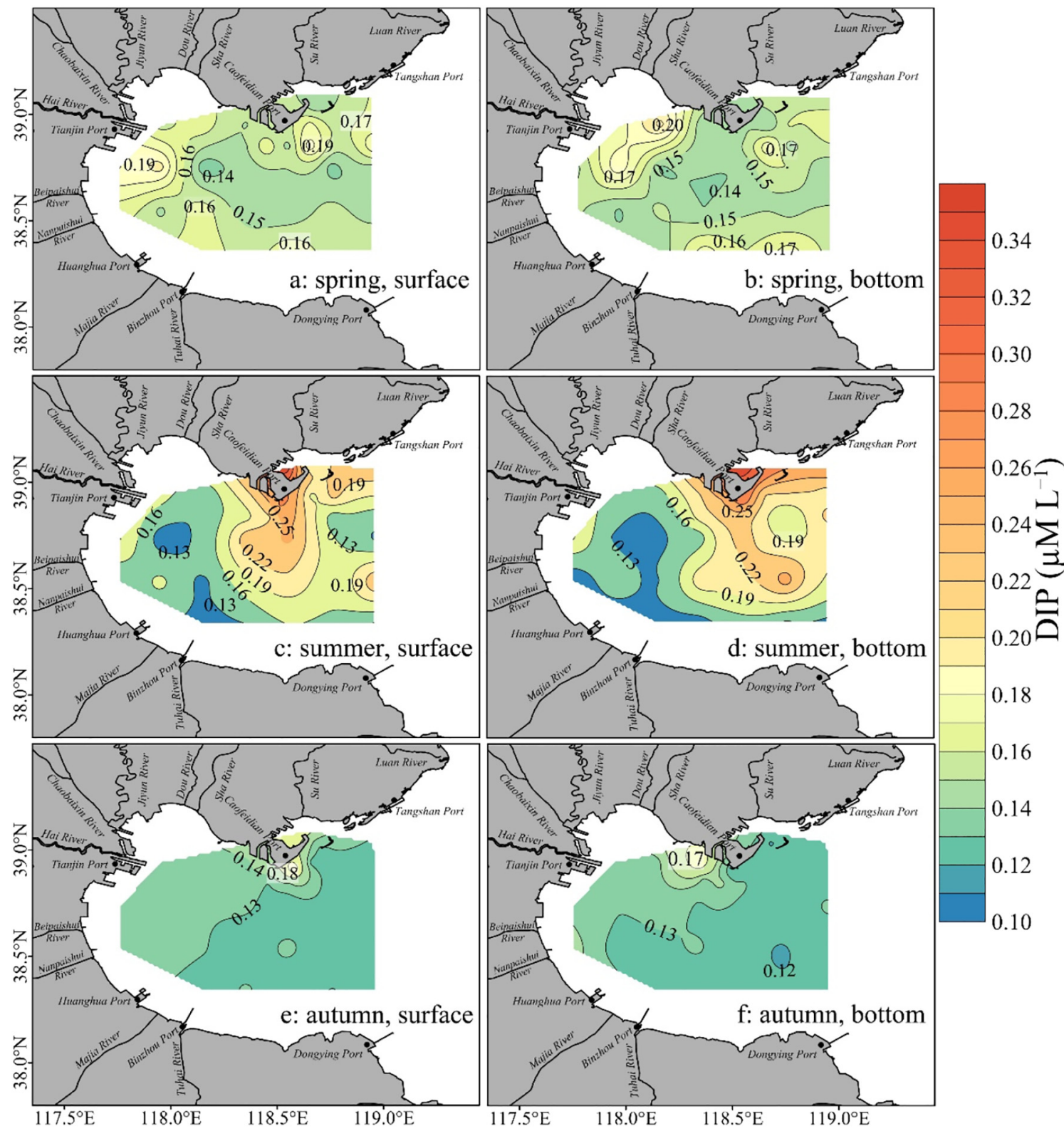

Fig. 7. The spatial distribution of DIP in BHB.

significantly high values near the Hai River Estuary. Liu et al. (2003) considered that river input is only one of the DIP sources in the Bohai Sea, with a contribution of $20 \%$ of the total DIP. In autumn 2013, more freshwater, which was discharged into the sea, might have diluted the DIP in the inshore waters; therefore, high concentrations were hard to distinguish. Meanwhile, in spring and summer 2014, the dilution was weak, and thus, the high DIP values could be distinguished (Fig. 7). The distribution of high DIP concentrations near Caofeidian was previously reported in the environmental monitoring work in the Bohai Sea; however, it was not fully explained (Qu, 2016). Since the impact of riverine input was not significant near Caofeidian, the coastal direct discharge seemed related to these high DIP values. Atmospheric deposition provided a contribution of $>70 \%$ to DIP in the Bohai Sea (Liu et al., 2003; Shou et al., 2018). Particularly near Caofeidian, the high atmospheric deposition occurred consistently throughout the entire year (Shou et al., 2018). This is a possible explanation for the high DIP values near Caofeidian (Fig. 7). Release from sediment resuspension was another important source of DIP in BHB. In spring, the strong north wind caused a significant disturbance in the southern shallow sea areas
(Chen et al., 2010), promoting sediment resuspension and causing the high turbidity in the area (Fig. 5). As a result, more $\mathrm{P}$ was released from the sediment to the overlying waters, which caused higher DIP concentrations in the southern BHB (Fig. 7). Recent studies have revealed that the flux of $\mathrm{P}$ between water and sediment was related to the DO concentration in the water column. Hypoxia could promote the release of P from sediment to seawater (Conley et al., 2002; Yang et al., 2012; Mu et al., 2017). A case study in the Hai River Estuary showed that the concentrations of DIP in the anoxic environment were about double those in the aerobic environment (Kang et al., 2018). Therefore, sediment in anoxic conditions served as important source of DIP and provided a contribution to the high values of DIP near Caofeidian, the central sea area, and the mouth of BHB in summer. Additionally, the consumption of phytoplankton was also a critical factor related to DIP distribution. In summer, there were relatively low DIP values distributed from Tianjin to the southern coastal waters, corresponding to high concentrations of Chl- $a$ there (Fig. 9), which was indicative of the phytoplankton consumption of DIP.

High values of DSi were rarely distributed near estuaries, suggesting 


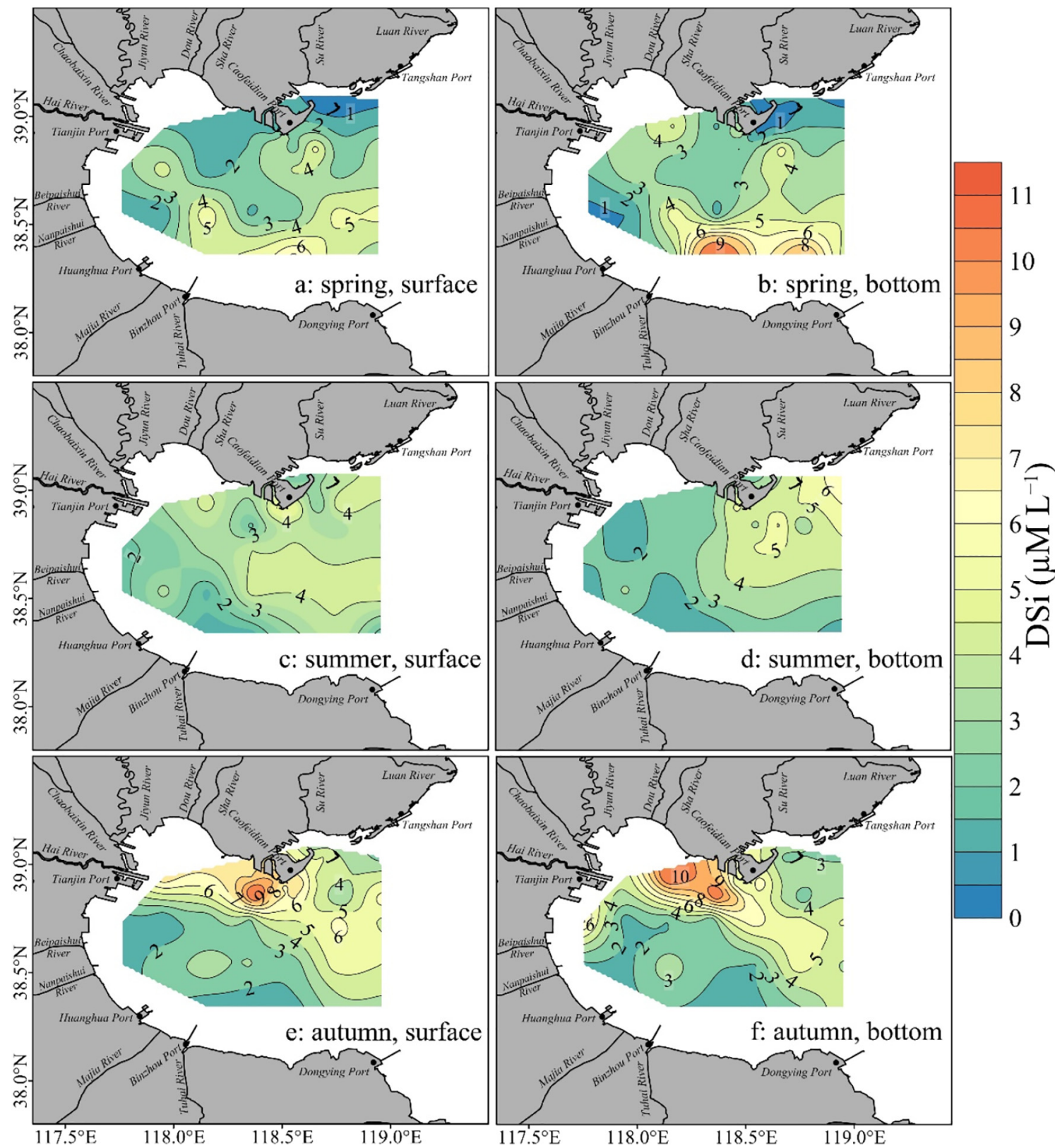

Fig. 8. The spatial distribution of DSi in BHB.

weak riverine impacts, which are probably related to the decline of runoff in recent decades (Ning et al., 2010). Sediment release is an important source of DSi in Bohai Sea (Liu et al., 2003). As shown in Fig. 8, the areas with high DSi concentrations, such as the southern coastal waters in spring, and the Caofeidian coastal waters and mouth of BHB in autumn, had higher concentrations at the bottom than at the surface, suggesting the sediment release of Si. The distribution of turbidity in spring indicated strong sediment resuspension in the southern coastal waters (Fig. 5), which corresponds to the high DSi values in this sea area. Huanghua coastal waters also showed strong sediment resuspension (Fig. 5) and relatively high DSi values (Fig. 8). The Si release from sediment to water could be further increased under low DO conditions (Belia et al., 2007; Couceiro et al., 2013). In the mouth of BHB, where DO of approximately $3 \mathrm{mg} \mathrm{L}^{-1}$ was distributed at the bottom in summer (Fig. 4), high DSi values were simultaneously observed (Fig. 8). There was also evidence suggesting the impact of circulation. Shan (1985) reported that a bottom current flowed into BHB along the northern coast, reached the surface near the central basin, and then moved southeastward until outside BHB. The cool water zone (approximately $24^{\circ} \mathrm{C}$, Fig. 2) and the low DO ( $<4 \mathrm{mg} \mathrm{L}^{-1}$, Fig. 4) located from the central basin to the mouth of BHB (Fig. 2) suggested the seawater upward movement, causing the high DSi values at the surface in this sea area (Fig. 8). Furthermore, these high DSi values at the surface extended from the central area to the mouth of BHB (Fig. 8), corresponding to the current flow outside of BHB.

\subsection{Seasonal variations of nutrients and their impact factors}

Seasonal variations in DIN with the highest values in spring, decrease in summer, and accumulation in autumn, and in DSi, with concentrations increasing from spring to autumn, were consistent with the results of previous studies (Wang et al., 2012; Qu, 2016). The seasonal variations in DIN were mainly related to terrestrial input and phytoplankton consumption. After accumulation during the entire winter, DIN started to decline in spring when the phytoplankton growth was promoted by the increasing temperature. The lowest values were 


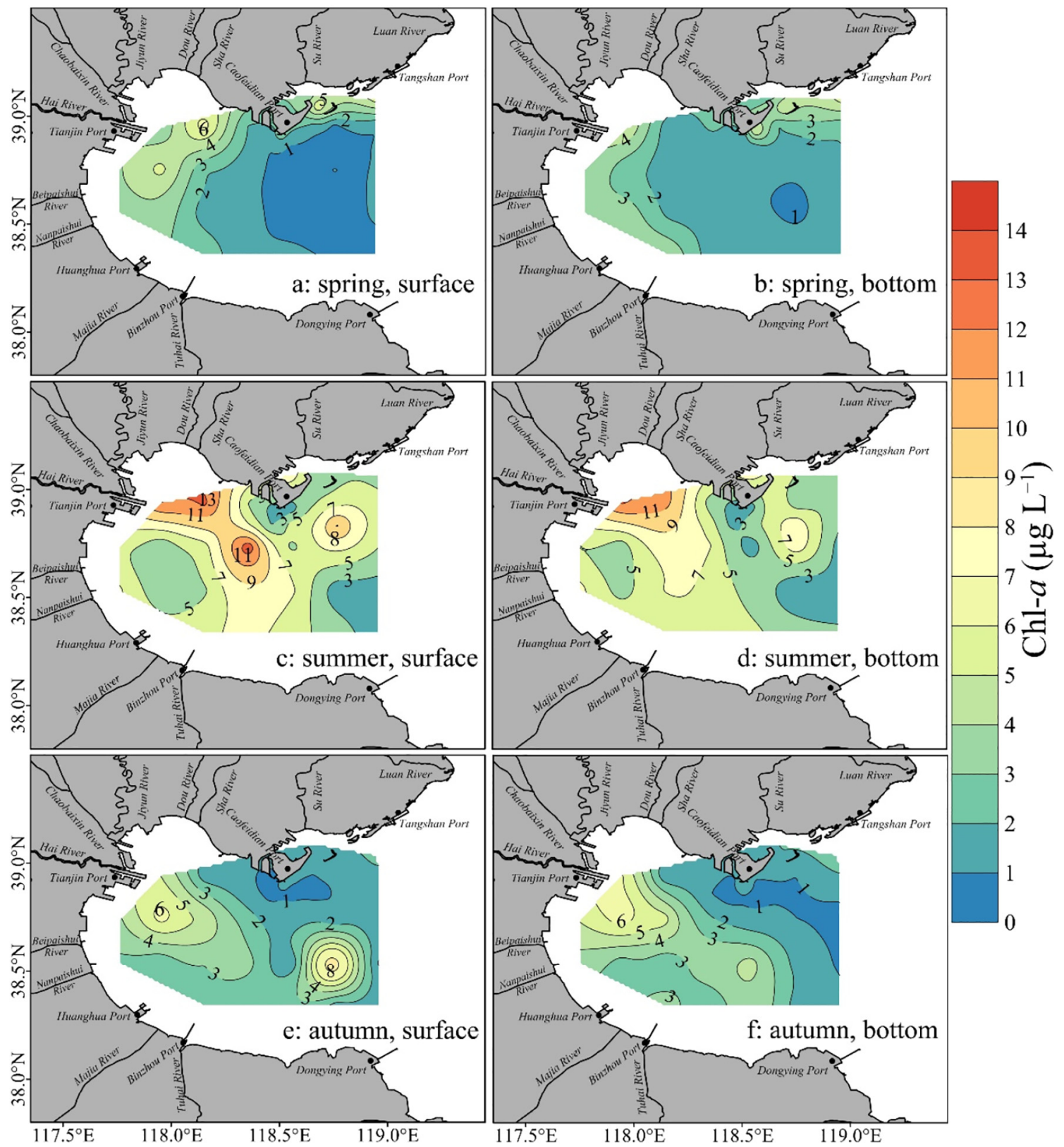

Fig. 9. The spatial distribution of Chl- $a$ in BHB.

ordinarily reached in summer but then showed recovery in autumn from the dead phytoplankton release and terrestrial loadings through coasts and rivers (Figs. 6, 9). DSi was consumed in spring with the first phytoplankton bloom, with diatoms as the dominant species, and then recovered in autumn as a result of the enhanced sediment release, supplemented through terrestrial inputs (Wang et al., 2014; Chen et al., 2016). For variations in DIP, in this study, the highest values were found in summer and the lowest values in autumn, different from previous studies that showed similar seasonal patterns in DIN and DIP (Wei et al., 2003). As revealed by the spatial distribution of salinity, there was significant impact from freshwater input in autumn rather than in summer because of the seasonal variation in runoff between 2013 and 2014. Therefore, more freshwater was discharged in autumn 2013, which diluted the seawater, and thus, generated the relatively low values of DIP. Meanwhile, in summer 2014, DIP was less diluted by riverine freshwater. Additionally, the low Chl- $a$ concentrations close to the Caofeidian Port played an important role in the high DIP concentrations in summer (Fig. 9).

\subsection{The partition of $B H B$ by nutrients}

The spatial and seasonal distributions of nutrients in this study showed that the sources and impact factors of DIN, DIP, and DSi varied in the western BHB, the southern BHB, the Caofeidian area, and the BHB mouth. PAM clustering analysis of nutrients indicated that sampling stations could be classified into two clusters (Fig. 10). Sampling stations in Cluster I were mostly distributed west of the $-15 \mathrm{~m}$ depth contour (western BHB), while stations in Cluster II were mostly distributed east of the $-15 \mathrm{~m}$ depth contour (eastern BHB). According to the independent $t$-test between the western and eastern BHB (Table 1), the significant differences were primarily identified in DIN in all three seasons at both surface and bottom. DIN in the western BHB was relatively high but low in the eastern BHB (Table 2). As discussed above, DIN largely originated from terrestrial inputs, and the greater terrestrial $\mathrm{N}$ input in the western coast is responsible for the high DIN values in the western BHB. Wang et al. (2009b) considered that two coastal currents dominated in western $\mathrm{BHB}$, which made it difficult for riverine 


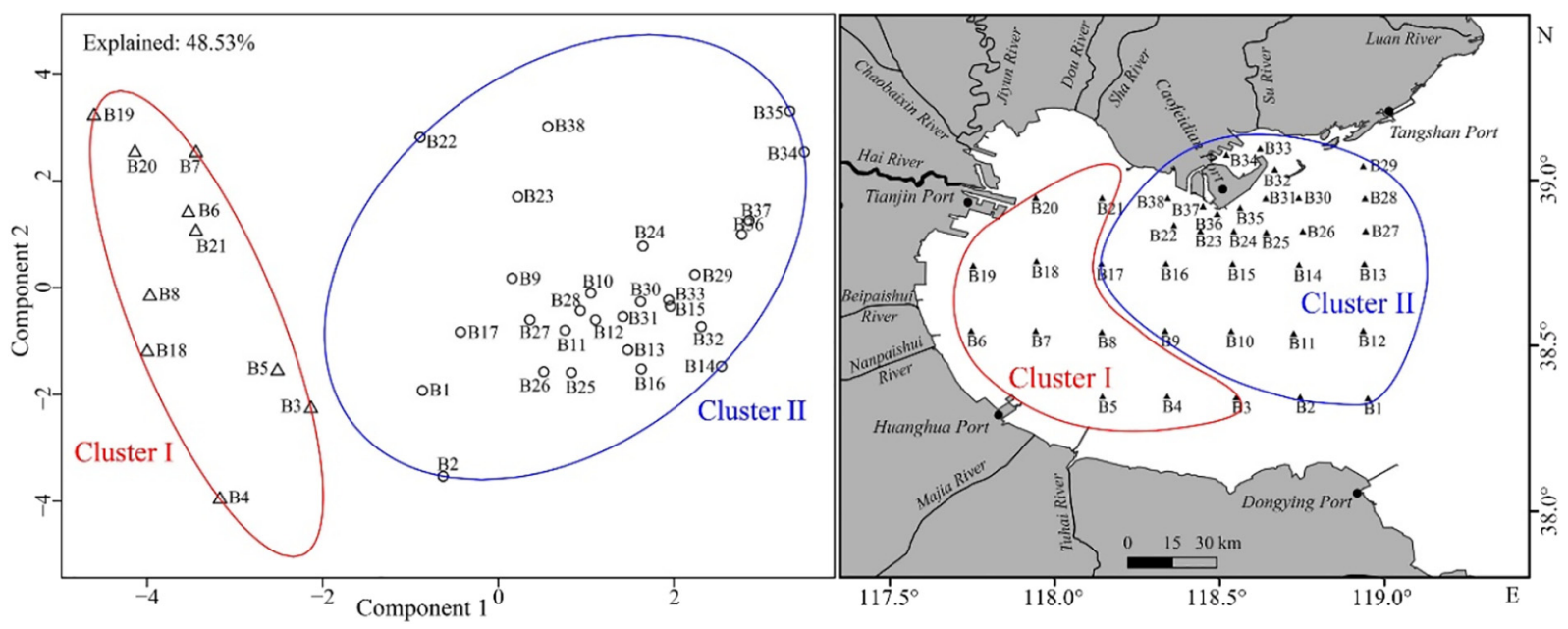

Fig. 10. PAM clustering analysis based on spatial pattern of nutrients in BHB.

Table 1

The independent $t$-test between western and eastern BHB. Significant differences $(p<0.05)$ are highlighted in bold.

\begin{tabular}{|c|c|c|c|}
\hline \multirow[t]{2}{*}{ Nutrient } & \multirow[t]{2}{*}{ Season } & \multicolumn{2}{|c|}{$p$ value (western vs. eastern $\mathrm{BHB}$ ) } \\
\hline & & Surface & Bottom \\
\hline \multirow[t]{3}{*}{ DIN } & Spring & 0.000 & 0.006 \\
\hline & Summer & 0.003 & 0.000 \\
\hline & Autumn & 0.002 & 0.002 \\
\hline \multirow[t]{3}{*}{ DIP } & Spring & 0.010 & 0.086 \\
\hline & Summer & 0.000 & 0.000 \\
\hline & Autumn & 0.173 & 0.623 \\
\hline \multirow[t]{3}{*}{ DSi } & Spring & 0.257 & 0.067 \\
\hline & Summer & 0.001 & 0.000 \\
\hline & Autumn & 0.014 & 0.316 \\
\hline
\end{tabular}

pollutants to be transported outside, further aggravating the situation of $\mathrm{N}$ pollution in the western BHB. Meanwhile for DIP and DSi, the significant differences between the western and eastern BHB existed mainly in summer (Table 1), with low values in the western BHB and high values in the eastern BHB (Table 2). DIP in the eastern BHB was mainly attributed to coastal direct discharge near Caofeidian, atmospheric deposition, and sediment release under low DO conditions, while DSi was more influenced by sediment release and circulation in summer. It could be summarized that the western BHB was a terrestrialinfluencing sea area, characterized by consistent high values of DIN. Meanwhile in the eastern BHB, the terrestrial factor was relatively weak and non-terrestrial factors were distinguished, characterized by seasonal high values of DIP and DSi.

The differences between the western and eastern BHB were also reflected by eutrophication and HABs. In China, BHB is one of the basins most threatened by eutrophication and HABs. Yu et al. (2015) assessed the eutrophication status in the Bohai Sea and showed that eutrophication in BHB was mostly distributed in the western inshore waters. During 2005-2014, there were 29 HABs reported in BHB, of which 25 were observed near Tianjin and Huanghua (Fig. 11). This is further supported by the HABs distribution during 1952-2014 (Song et al., 2016). The partition of BHB, based on nutrients, is essential for the blue bay regulation of BHB. Western inshore waters, due to serious terrestrial impacts and $\mathrm{N}$ pollution, should be treated as key sea areas for seawater quality improvement. The coastal zones and rivers surrounding the western coast need immediate and effective action to control terrestrial pollution loads.

\subsection{Long-term changes of nutrients}

For decades, the Bohai Sea has been experiencing significant changes in nutrient regime: increase in DIN and decreases in DIP and DSi (Jiang et al., 2005; Ning et al., 2010). For BHB, a similar trend was also exhibited by both mean concentrations (Table 3 ) and seasonal concentrations (Fig. 12). From 1982 to 2013, DIN increased nearly 7 times, while DIP and DSi decreased 7 and 11 times, respectively (Table 3). In previous studies, the long-term change of nutrients was ordinarily associated with multiple human activities (Ning et al., 2010). Particularly for N, sewage discharge, fertilizer usage, and marine culture are important factors (Song, 2010). As Fig. 13 illustrates, industrial wastewater discharge exhibited a fluctuating decline, while the domestic wastewater discharge increased sharply, nearly doubling from 2003 to 2015. Song (2010) considered that the improvement in sewage treatment capacity in recent years was helpful for wastewater discharge reduction and seawater quality improvement, which explained the decline in industrial wastewater discharge. However, coastal zones

Table 2

The nutrients (mean $\pm \mathrm{SD}, \mu \mathrm{M} \mathrm{L}^{-1}$ ) in western and eastern BHB. Concentrations with significant differences are highlighted in bold.

\begin{tabular}{|c|c|c|c|c|c|}
\hline \multirow[t]{2}{*}{ Nutrient } & \multirow[t]{2}{*}{ Season } & \multicolumn{2}{|l|}{ Surface } & \multicolumn{2}{|l|}{ Bottom } \\
\hline & & Western & Eastern & Western & Eastern \\
\hline \multirow[t]{3}{*}{ DIN } & Spring & $23.58 \pm 8.49$ & $12.89 \pm 4.77$ & $26.69 \pm 13.51$ & $11.48 \pm 4.39$ \\
\hline & Summer & $13.48 \pm 6.72$ & $5.19 \pm 2.78$ & $13.04 \pm 4.77$ & $6.64 \pm 2.92$ \\
\hline & Autumn & $14.33 \pm 4.15$ & $8.59 \pm 2.81$ & $15.19 \pm 5.65$ & $7.86 \pm 2.70$ \\
\hline \multirow[t]{3}{*}{ DIP } & Spring & $0.17 \pm 0.15$ & $0.15 \pm 0.13$ & $0.16 \pm 0.02$ & $0.15 \pm 0.01$ \\
\hline & Summer & $0.15 \pm 0.03$ & $0.21 \pm 0.06$ & $0.14 \pm 0.03$ & $0.22 \pm 0.06$ \\
\hline & Autumn & $0.13 \pm 0.00$ & $0.14 \pm 0.02$ & $0.13 \pm 0.01$ & $0.13 \pm 0.01$ \\
\hline \multirow[t]{3}{*}{ DSi } & Spring & $3.58 \pm 2.25$ & $2.67 \pm 1.45$ & $4.64 \pm 4.19$ & $2.76 \pm 1.96$ \\
\hline & Summer & $2.26 \pm 1.06$ & $3.73 \pm 1.11$ & $1.82 \pm 0.81$ & $4.00 \pm 1.38$ \\
\hline & Autumn & $2.94 \pm 2.53$ & $5.31 \pm 2.36$ & $3.75 \pm 3.48$ & $4.72 \pm 2.27$ \\
\hline
\end{tabular}




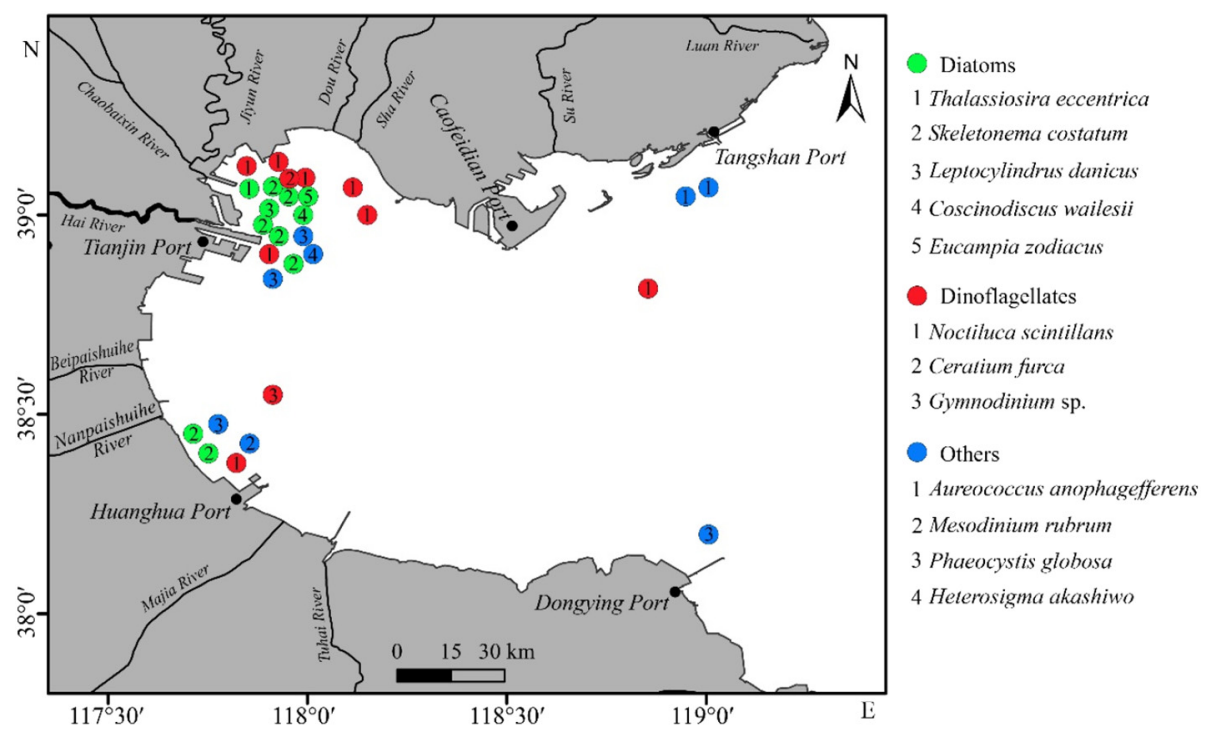

Fig. 11. The spatial distribution of HABs and causing species during 2005-2014 (State Oceanic Administration of China, 2005-2014).

Table 3

Long-term variations of nutrient concentrations $\left(\mu \mathrm{ML}^{-1}\right)$.

\begin{tabular}{llrrrl}
\hline Year & Month & \multicolumn{1}{c}{ DIN } & DIP & DSi & Reference \\
\hline 1982 & $5,8,10$ & 1.59 & 1.18 & 40.59 & Jiang et al., 2005 \\
1992 & $5,8,10$ & 5.10 & 0.26 & 10.69 & Jiang et al., 2005 \\
1998 & $5,8,10$ & 7.25 & 0.31 & 17.43 & Jiang et al., 2005 \\
$2013-2014$ & $5,8,10$ & 11.04 & 0.16 & 3.70 & This study \\
\hline
\end{tabular}

surrounding the Bohai Sea experienced rapid urbanization (Fan et al., 2013), increasing urban domestic pollution, and seriously impacting seawater quality (Wang et al., 2011; Tong et al., 2014; Zhao et al., 2018). In addition, marine culture surrounding BHB exhibited a continual increase during 2003-2015 (Fig. 13) and also provided a nonnegligible contribution. Therefore, domestic wastewater and marine culture are two important factors related to the increase in $\mathrm{N}$ and should be further improved in the regulation of blue bay in BHB. The decreases in DIP and DSi were largely related to the runoff of the Hai River Basin, which in the 2000 s was only $11.5 \%$ of the value during the 1950s (Wei et al., 2016). DIP was additionally affected by the ban of phosphorus-containing detergents since 2002 and the increase in sewage treatment capacity (Ning et al., 2010; Song, 2010). Although land reclamation was considered an important anthropogenic perturbation in BHB after 2000, its impact was not significant, and it did not change the development trends of nutrients in recent years. A case study in Caofeidian revealed that extensive reclamation caused nutrient
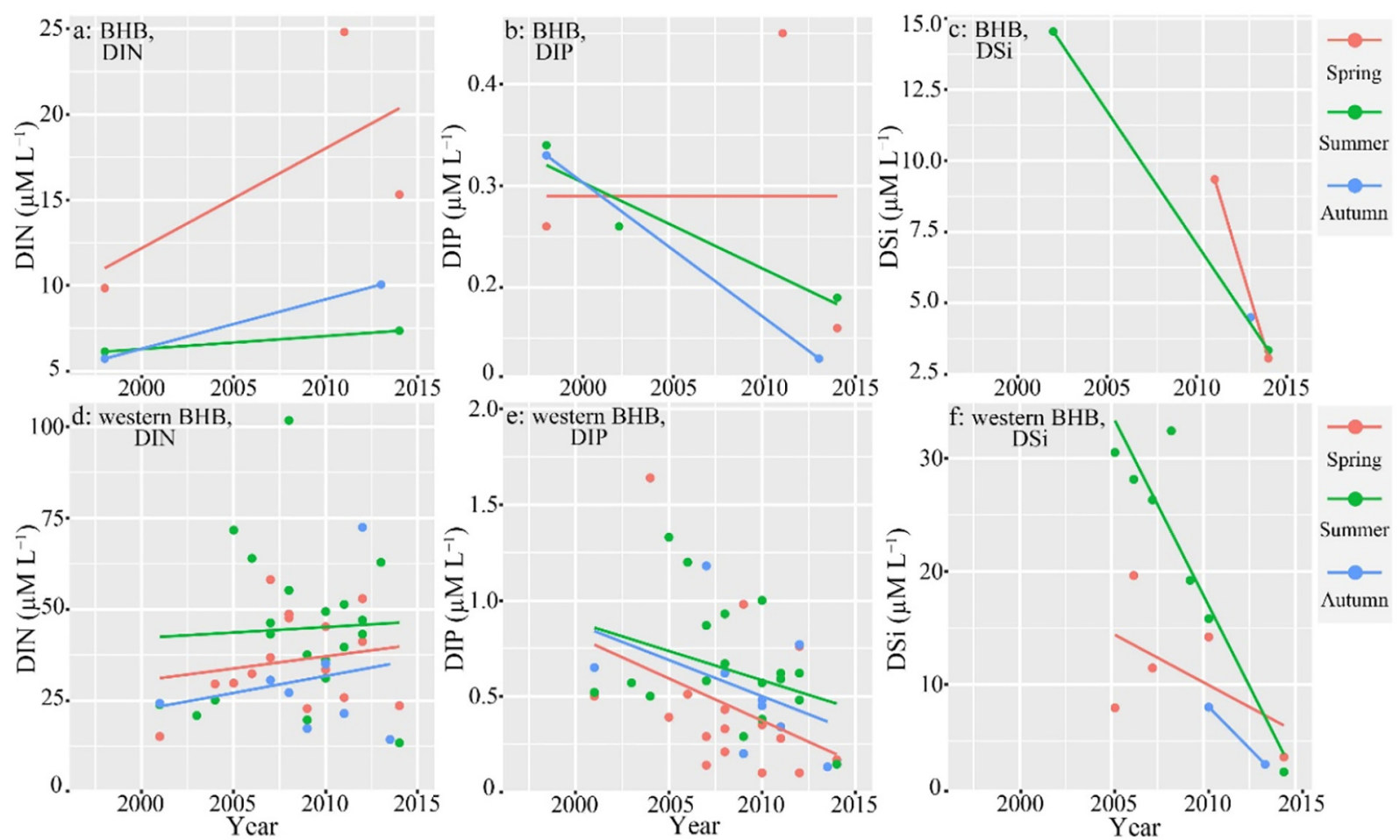

Fig. 12. Long-term changes of nutrients in BHB. DIN (a), DIP (b) and DSi (c) in BHB; DIN (d), DIP (e) and DSi (f) in western BHB (Cluster I in Fig. 10). Data were from Wang (2003), Shen et al. (2004), Wang et al. (2009a), Li et al. (2012), Peng (2015), Yin et al. (2015) and this study. 

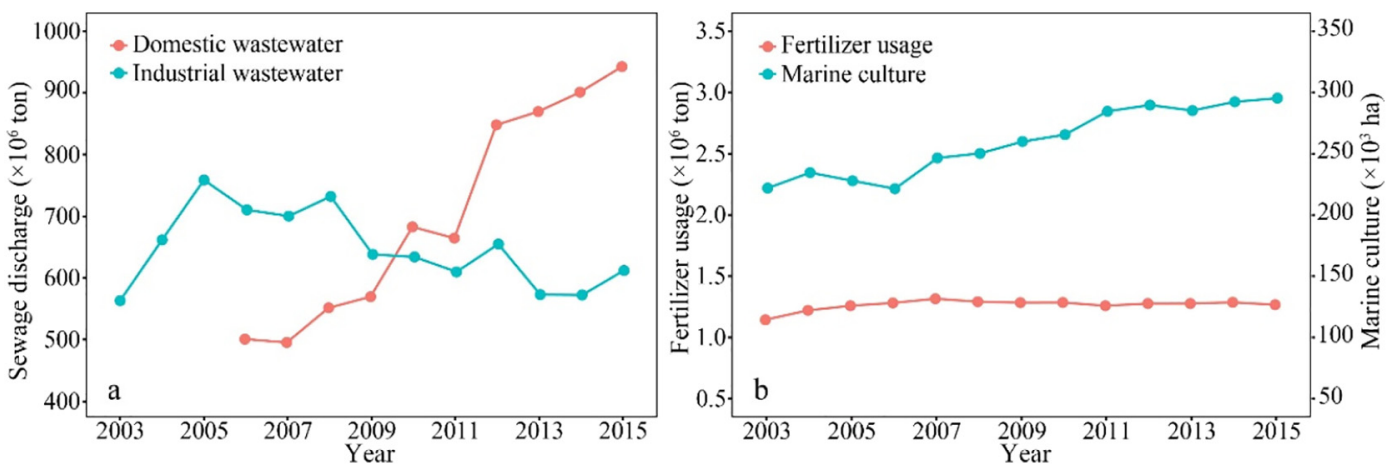

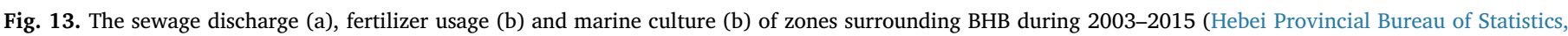

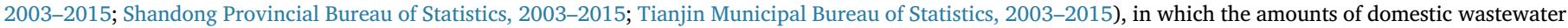
in Tangshan and Cangzhou were missing.

redistribution in adjacent seawaters (Liu et al., unpublished), suggesting that the impact of reclamation may only be distinguished near the reclamation area.

Another case study in Jiaozhou Bay has also revealed that the longterm change in nutrients further included seasonal variations, which could be summarized as rapid changes in DIN and DSi in summer and autumn but slow changes in spring and winter (Sun et al., 2011). As shown in Fig. 12, seasonal variations were also exhibited in this study, especially in the western BHB (Cluster I), which had more seasonal available data. The changing trends in DIN and DIP in spring and autumn were relatively faster than those in summer, while DSi showed a sharp decline in summer. Such seasonal variations were probably related to the changes in precipitation. Chu et al. (2010b) indicated that summer experienced a significant decreasing trend in precipitation $(p<0.05)$, which was significantly faster than in spring, autumn, and winter. Therefore, with rapidly decreasing precipitation in summer, $\mathrm{Si}$, which mainly originates from rock weathering, was not easily transported into rivers and coastal seas, causing a sharp decrease in DSi in summer. For DIN, due to its continual increase driven by multiple human activities, the decline in precipitation provided difficulty for the transport of $\mathrm{N}$ and, thus, led to a gentle increase in DIN in summer. Meanwhile, for DIP, a gentle decrease was also observed in summer, which was possibly related to the anoxic condition in BHB. As reported in Zhang et al. (2016) and discussed above, DO in summer was rather low, even in the inshore waters where vertical mixing was relatively strong. In anoxic conditions, the DIP concentration in the water column could be twice that in the aerobic environment (Kang et al., 2018). The supply of $\mathrm{P}$ from sediment in summer mitigated the decrease in DIP in BHB.

\section{Conclusions}

Through three cruises in the spring, summer, and autumn in BHB, high values of DIN were found to be consistently distributed in the western inshore waters, which are mainly related to terrestrial inputs and atmospheric deposition. DIP was jointly affected by terrestrial inputs, sediment release, and atmospheric deposition, with high concentrations occurring in the inshore coastal waters in spring, near Caofeidian in summer and autumn. DSi exhibited high values near the southern coasts in spring, in the northern and central BHB in summer, and near Caofeidian in autumn, mainly associated with sediment release. Based on the spatial pattern of nutrients, BHB could be partitioned into western and eastern parts, with $-15 \mathrm{~m}$ depth as the separation. The western BHB were primarily impacted by terrestrial factors, with consistent high DIN concentrations in the three seasons and should be treated as the key sea area in blue bay regulation. The eastern BHB was characterized by seasonal high values of DIP and DSi, a result of terrestrial and non-terrestrial factors, e.g., coastal direct discharge and sediment release. Long-term changes in nutrients since 2000 showed a similar developmental trend as that before 2000: an increase in DIN and decreases in DIP and DSi. Domestic wastewater discharge and marine culture were two important factors driving $\mathrm{N}$ increase and should be improved in further blue bay regulation. A seasonal variation of long-term changes was exhibited with a rapid change in DSi and slow changes in DIN and DIP in summer, which were related to the sharp decline in precipitation and the supply of sediment release.

\section{Acknowledgements}

We appreciate all the colleagues in Key Laboratory of Coastal Zone Environmental Processes and Ecological Remediation (YIC, CAS) for their help in sampling and analysis. This work was jointly supported by the Natural Science Foundation of China (41106101 and 41776126), the Cooperation Project of Chinese Academy of Sciences and Hebei Academy of Sciences (161304) and the Key Deployment Project of Chinese Academy of Sciences (KZZD-EW-14).

\section{References}

Belia, C., Dassenakis, M., Scoullos, M., 2007. Study of the N, P and Si fluxes between fish farm sediment and seawater. Results of simulation experiments employing a benthic chamber under various redox conditions. Mar. Chem. 103, 266-275.

Bian, C.W., Jiang, W.S., Pohlmann, T., Sündermann, J., 2016. Hydrography-physical description of the Bohai Sea. J. Coast. Res. 74, 1-12.

Bran + Luebbe, 2008a. AutoAnalyzer Method No. G-173-196 Rev.9, Nitrite (Multitest MT 18).

Bran + Luebbe, 2008b. AutoAnalyzer Method No. G-172-196 Rev.11, Nitrate (Multitest MT 19).

Bran + Luebbe, 2008c. AutoAnalyzer Method No. G-171-196 Rev.12, Ammonia (Multitest MT 19).

Bran + Luebbe, 2008d. AutoAnalyzer Method No. G-175-196 Rev.13, Phosphate and Total Dissolved Phosphate (Multitest MT 19).

Bran + Luebbe, 2008e. AutoAnalyzer Method No. G-177-196 Rev.9, Silicate (Multitest MT 19).

Carpenter, S.R., Bennett, E.M., 2011. Reconsideration of the planetary boundary for phosphorus. Environ. Res. Lett. 6, 014009.

Chen, X.L., Lu, J.Z., Cui, T.W., Jiang, W.S., Tian, L.Q., Chen, L.Q., Zhao, W.J., 2010. Coupling remote sensing retrieval with numerical simulation for SPM study-taking Bohai Sea in China as a case. Int. J. Appl. Earth Obs. 12, S203-S211.

Chen, Y.H., Gao, Y.H., Chen, C.P., Liang, J.R., Sun, L., Zhen, Y., Qiao, L., 2016. Seasonal variations of phytoplankton assemblages and its relation to environmental variables in a scallop culture sea area of Bohai Bay, China. Mar. Pollut. Bull. 113, 362-370.

Chu, J.T., Xia, J., Xu, C.Y., Singh, V.P., 2010a. Statistical downscaling of daily mean temperature, pan evaporation and precipitation for climate change scenarios in Haihe River, China. Theor. Appl. Climatol. 99, 149-161.

Chu, J.T., Xia, J., Xu, C.Y., Li, L., Wang, Z.G., 2010b. Spatial and temporal variability of daily precipitation in Haihe River basin, 1958-2007. J. Geogr. Sci. 20, 248-260.

Cloern, J.E., Abreu, P.C., Carstensen, J., Chauvaud, L., Elmgren, R., Grall, J., Greening, H., Johansson, J.O.R., Kahru, M., Sherwood, E.T., 2016. Human activities and climate variability drive fast-paced change across the world's estuarine-coastal ecosystems. Glob. Chang. Biol. 22, 513-529.

Conley, D.J., Humborg, C., Rahm, L., Savchuk, O.P., Wulff, F., 2002. Hypoxia in the Baltic Sea and basin-scale changes in phosphorus biogeochemistry. Environ. Sci. Technol. 
$36,5315-5320$

Couceiro, F., Fones, G.R., Thompson, C.E.L., Statham, P.J., Sivyer, D.B., Parker, R., KellyGerreyn, B.A., Amos, C.L., 2013. Impact of resuspension of cohesive sediments at the Oyster Grounds (North Sea) on nutrient exchange across the sediment-water interface. Biogeochemistry 113, 37-52.

De Vries, W., Kros, J., Kroeze, C., Seitzinger, S.P., 2013. Assessing planetary and regional nitrogen boundaries related to food security and adverse environmental impacts. Curr. Opin. Environ. Sustain. 5, 392-402.

Department of Water Resources of Hebei Province, 2013-2014. Hebei Water Resources Bulletin. http://www.hebwater.gov.cn (in Chinese).

Fan, J.F., Ma, T., Zhou, C.H., Zhou, Y.K., 2013. Changes in spatial patterns of urban landscape in Bohai Rim from 1992 to 2010 using DMSP-OLS data. J. Geo-inf. Sci. 15, 280-288 (in Chinese with English abstract).

Glibert, P.M., 2017. Eutrophication, harmful algae and biodiversity-challenging paradigms in a world of complex nutrient changes. Mar. Pollut. Bull. 124, 591-606.

Hebei Provincial Bureau of Statistics, 2003-2015. Hebei Statistic Yearbook. China Statistics Press, Beijing (in Chinese).

Huang, D.J., Su, J.L., Backhaus, J.O., 1999. Modelling the seasonal thermal stratification and baroclinic circulation in the Bohai Sea. Cont. Shelf Res. 19, 1485-1505.

Huang, J.L., Li, Q.S., Huang, L., Zhang, Z.F., Mu, J.L., Huang, Y.L., 2013. Watershed-scale evaluation for land-based nonpoint source nutrients management in the Bohai Sea Bay, China. Ocean Coast. Manag. 71, 314-325.

Jiang, H., Cui, Y., Chen, B.J., Chen, J.F., Song, Y.L., 2005. The variation trend of nutrient salts in the Bohai Sea. Mar. Fish. Res. 26, 61-67 (in Chinese with English abstract).

Kang, M.X., Peng, S., Tian, Y.M., Zhang, H.Y., 2018. Effects of dissolved oxygen and nutrient loading on phosphorus fluxes at the sediment-water interface in the Ha River estuary, China. Mar. Pollut. Bull. 130, 132-139.

Li, G.J., Ma, Y.L., Li, W., Wang, J.N., Wei, H., 2012. Distribution of inorganic nutrients and potential eutrophication assessment in Bohai Bay in spring. J. Tianjin Univ. Sci. Technol. 27, 22-27 (in Chinese with English abstract).

Lin, Q.L., Song, Y.L., Yang, Q.F., Cui, Y., Xin, Z.H., Yi, M.M., 1991. The hydrochemical environments in Bohai Sea. Prog. Fish. Sci. 12, 11-30 (in Chinese with English abstract).

Lin, L., Liu, D.Y., Liu, Z., Gao, H.W., 2016. Impact of land reclamation on marine hydrodynamic and ecological environment. Haiyang Xuebao 38, 1-11 (in Chinese with English abstract).

Liu, S.M., Zhang, J., Jiang, W.S., 2003. Pore water nutrient regeneration in shallow coastal Bohai Sea, China. J. Oceanogr. 59, 377-385.

Liu, S.M., Li, L.W., Zhang, Z.N., 2011. Inventory of nutrients in the Bohai Sea. Cont. Shelf Res. 31, 1790-1797.

Liu, K.X., Wang, H., Fu, S.J., Gao, Z.G., Dong, J.X., Feng, J.L., Gao, T., 2017. Evaluation of sea level rise in Bohai Bay and associated responses. Adv. Clim. Chang. Res. 8, 48-56.

Lorenzen, C.J., 1967. Determination of chlorophyll and pheo-pigments: spectrophotometric equations. Limnol. Oceanogr. 12, 343-346.

Lv, X.C., Yuan, D.K., Ma, X.D., Tao, J.H., 2014. Wave characteristics analysis in Bohai Sea based on ECMWF wind field. Ocean Eng. 91, 159-171.

Millero, F.J., 2013. Chemical Oceanography. CRC press, Boca Raton, Florida, pp. 1-54.

Mu, D., Yuan, D.K., Feng, H., Xing, F.W., Teo, F.Y., Li, S.Z, 2017. Nutrient fluxes across sediment-water interface in Bohai Bay coastal zone, China. Mar. Pollut. Bull. 114, 705-714.

Nie, H.T., Tao, J.H., 2009. Eco-environment status of the Bohai Bay and the impact of coastal exploitation. Mar. Sci. Bull. 11, 81-96.

Ning, X.R., Lin, C.L., Su, J.L., Liu, C.G., Hao, Q., Le, F.F., Tang, Q.S., 2010. Long-term environmental changes and the responses of the ecosystems in the Bohai Sea during 1960-1996. Deep Sea Res., Part II 57, 1079-1091.

Oksanen, J., Blanchet, G., Friendly, M., Kindt, R., Legendre, P., McGlinn, D., Minchin, P.R., Hara, R.B., Simpson, G.L., Solymos, P., Stevens, M.H.H., Szoecs, E., Wagner, H., 2016. Vegan: Community Ecology Package. R Package Version 2.4-1.

Pelling, H.E., Uehara, K., Green, J.A.M., 2013. The impact of rapid coastline changes and sea level rise on the tides in the Bohai Sea, China. J. Geophys. Res. Oceans 118, 3462-3472.

Peng, S.T., 2015. The nutrient, total petroleum hydrocarbon and heavy metal contents in the seawater of Bohai Bay, China: temporal-spatial variations, sources, pollution statuses, and ecological risks. Mar. Pollut. Bull. 95, 445-451.

Qu, K.M., 2016. Altas of Eco-environment in the Bohai Sea. Science Press, Beijing, pp. 41-72 (in Chinese).

R Core Team, 2017. R: A Language and Environment for Statistical Computing. R Foundation for Statistical Computing, Vienna, Austria.

Shan, G.L., 1985. The circulation in summer of Bohai Bay. Ocean Technol. 4, 35-47 (in Chinese with English abstract).

Shandong Provincial Bureau of Statistics, 2003-2015. Shandong Statistic Yearbook. China Statistics Press, Beijing (in Chinese).

Shen, Z.L., 1999. Hydrochemical elements in Bohai Bay and its eastern part waters. Stud. Mar. Sin. 41, 51-59 (in Chinese with English abstract).

Shen, Y.L., Zhang, H., Ma, X., Kong, D.W., Ma, L.N., 2004. The influence for the ocean primary yield-power (chlorofucine) with the change of inorganic nitrogen and reactive phosphate in the Bohai Ocean Gulf. Environ. Monit. China 20, 52-54 (in Chinese with English abstract).

Shi, J.H., Li, G.X., Wang, P., 2011. Anthropogenic influences on the tidal prism and water exchanges in Jiaozhou Bay, Qingdao, China. J. Coast. Res. 27, 57-72.

Shou, W.W., Zong, H.B., Ding, P.X., Hou, L.J., 2018. A modelling approach to assess the effects of atmospheric nitrogen deposition on the marine ecosystem in the Bohai Sea. Estuar. Coast. Mar. Sci. 208, 36-48.

Song, J.M., 2010. Biogeochemical Processes of Biogenic Elements in China Marginal Seas. Zhejiang University Press, Hangzhou, pp. 163-213.
Song, N.Q., Wang, N., Lu, Y., Zhang, J.R., 2016. Temporal and spatial characteristics of harmful algal blooms in the Bohai Sea during 1952-2014. Cont. Shelf Res. 122, $77-84$.

State Oceanic Administration of China, 2005-2014. Bulletin of China's Marine Environmental Status. http://www.nmdis.org.cn/gongbao/huanjing (in Chinese).

Sun, X.X., Sun, S., Zhao, Z.X., Shen, Z.L., 2011. Long-term changes in nutrient concentration and structure in the Jiaozhou Bay. Oceanol. Limnol. Sin. 42, 662-669 (in Chinese with English abstract).

Tianjin Municipal Bureau of Statistics, 2003-2015. Tianjin Statistic Yearbook. China Statistics Press, Beijing (in Chinese).

Tong, S.Q., Song, N.Q., Yan, H.K., Fu, Q., 2014. Management measures and recommendations in improving the Bohai Sea environment over the last quarter century. Ocean Coast. Manag. 91, 80-87.

Tsutsumi, H., 2006. Critical events in the Ariake Bay ecosystem: clam population collapse, red tides, and hypoxic bottom water. Plankon Benthos Res. 1, 3-25.

Wang, J., 2003. Species composition and quantity variation of phytoplankton in inshore waters of the Bohai Sea. Mar. Fish. Res. 24, 44-50 (in Chinese with English abstract).

Wang, X.L., Cui, Z.G., Guo, Q., Han, X.R., Wang, J.T., 2009a. Distribution of nutrients and eutrophication assessment in the Bohai Sea of China. Chin. J. Oceanol. Limnol. 27, 177-183.

Wang, Y., Wu, D.X., Lin, X.P., Zheng, P.N., 2009b. Numerical study on the time of water exchange and the variation of pollutants' concentration in Bohai bay under the effect of M2 constituent. In: International Conference on Bioinformatics and Biomedical Engineering (ICBBE 2009), pp. 1-5.

Wang, T.Y., Lu, Y.L., Chen, C.L., Naile, J.E., Khim, J.S., Park, J., Luo, W., Jiao, W.T., Hu, W.Y., Giesy, J.P., 2011. Perfluorinated compounds in estuarine and coastal areas of north Bohai Sea, China. Mar. Pollut. Bull. 62, 1905-1914.

Wang, Y.J., Liu, D.Y., Dong, Z.J., Di, B.P., Shen, X.H., 2012. Temporal and spatial distributions of nutrients under the influence of human activities in Sishili Bay, northern Yellow Sea of China. Mar. Pollut. Bull. 64, 2708-2719.

Wang, H.J., Wang, A.M., Bi, N.S., Zeng, X.M., Xiao, H.H., 2014. Seasonal distribution of suspended sediment in the Bohai Sea, China. Cont. Shelf Res. 90, 17-32.

Wang, Y.Z., Wu, D., Shi, H.F., Zhao, X.L., Yan, W.W., 2015. Impact of reclamation on water exchange in Bohai Bay in recent decade. Oceanol. Limnol. Sin. 46, 471-480 (in Chinese with English abstract).

Wei, H., Zhao, L., Feng, S.Z., 2003. Annual cycle of phytoplankton biomass and primary production in the Bohai Sea simulated by a three-dimensional ecosystem model. Acta Oceanol. Sin. 25, 66-72 (in Chinese with English abstract).

Wei, Q., Sun, C.H., Wu, G.H., Pan, L., 2016. Haihe River discharge to Bohai Bay, North China: trends, climate, and human activities. Hydrol. Res. 48, 1058-1070.

Wickham, H., 2016. ggplot2: Elegant Graphics for Data Analysis. Springer-Verlag, New York, USA.

Wu, D.X., Wan, X.Q., Bao, X.W., Mou, L., Lan, J., 2004. Comparison of temperature, salinity and circulation in summer between 1958 and 2000 in Bohai Sea. Chin. Sci. Bull. 49, 363-369.

Yang, B., Wang, B.D., Wei, Q.S., Sun, X., 2012. Impact of hypoxia on biogeochemical cycling of biogenic elements in sediment. Mar. Sci. 36, 124-129 (in Chinese with English abstract).

Yin, C.L., Zhang, Q.F., Kan, W.J., Zhang, Y.N., 2015. Nutrient variation and eutrophication assessment of Bohai Bay in Tianjin. J. Tianjin Univ. Sci. Technol. 30, 56-61 (in Chinese with English abstract).

Yu, C.Y., Li, M., Bao, C.G., Lan, D.D., Xu, Y., Ma, M.H., 2015. Evaluation and risk prediction of eutrophication in Bohai Sea. Mar. Environ. Sci. 34, 373-376 (in Chinese with English abstract).

Zhai, W.D., Zhao, H.D., Zheng, N., Xu, Y., 2012. Coastal acidification in summer bottom oxygen-depleted waters in northwestern-northern Bohai Sea from June to August in 2011. Chin. Sci. Bull. 57, 1062-1068.

Zhang, H., Lin, C., Lei, P., Shan, B.Q., Zhao, Y., 2015. Evaluation of river eutrophication of the Haihe River basin. Acta Sci. Circumst. 35, 2336-2344 (in Chinese with English abstract).

Zhang, H., Li, Y.F., Tang, C., Zou, T., Yu, J., Guo, K., 2016. Spatial characteristics and formation mechanisms of bottom hypoxia zone in the Bohai Sea during summer. Chin. Sci. Bull. 61, 1612-1620 (in Chinese with English abstract).

Zhang, P., Su, Y., Liang, S.K., Li, K.Q., Li, Y.B., Wang, X.L., 2017. Assessment of long-term water quality variation affected by high-intensity land-based inputs and land reclamation in Jiaozhou Bay, China. Ecol. Indic. 75, 210-219.

Zhao, B.R., Zhuang, G.W., Cao, D.M., 1995. Circulation, tidal residual currents and their effects on the sedimentations in the Bohai Sea. Oceanol. Limnol. Sin. 26, 466-473 (in Chinese with English abstract).

Zhao, S.J., Jiao, N.Z., Shen, Z.L., Wu, Y.L., 2005. Causes and consequences of changes in nutrient structure in the Jiaozhou Bay. J. Integr. Plant Biol. 47, 396-410.

Zhao, H.D., Kao, S.J., Zhai, W.D., Zang, K.P., Zheng, N., Xu, X.M., Huo, C., Wang, J.Y., 2017. Effects of stratification, organic matter remineralization and bathymetry on summertime oxygen distribution in the Bohai Sea, China. Cont. Shelf Res. 134, 15-25.

Zhao, H.X., Cui, J.X., Wang, S.F., Lindley, S., 2018. Customizing the coefficients of urban domestic pollutant discharge and their driving mechanisms: evidence from the Taihu Basin, China. J. Environ. Manag. 213, 247-254.

Zhu, L.H., Wu, J.Z., Xu, Z.Q., Xu, Y.C., Lin, J., Hu, R.J., 2014. Coastline movement and change along the Bohai Sea from 1987 to 2012. J. Appl. Remote. Sens. 8, 083585.

Zhu, G.R., Xie, Z.L., Xu, X.G., Ma, Z.W., Wu, Y.L., 2016. The landscape change and theory of orderly reclamation sea based on coastal management in rapid industrialization area in Bohai Bay, China. Ocean Coast. Manag. 133, 128-137.

Zou, J.Z., Dong, L.P., Qin, B.P., 1983. Preliminary studies on eutrophication and red tide problems in Bohai Bay. Hydrobiologia 2, 41-54 (in Chinese with English abstract). 